\title{
Export Diversification Effects of the WTO Trade Facilitation Agreement
}

\author{
Cosimo Beverelli 1 \\ Simon Neumueller2 \\ Robert Teh ${ }^{3}$
}

\begin{abstract}
We estimate the effects of trade facilitation on export diversification, as measured by two extensive margins: the number of products exported by destination and the number of export destinations served by product. To address the issue of causality, we employ an identification strategy whereby only exports of new products, or exports to new destinations, are taken into account when computing the respective margins of trade. We find a positive impact of trade facilitation on the extensive margins of trade. The results are robust to alternative definitions of extensive margins, different sets of controls and various estimation methods. Simulation results suggest substantial extensive margin gains from trade facilitation reform in SubSaharan Africa and Latin America and the Caribbean.
\end{abstract}

JEL : $\quad$ F13, F14, F17

Keywords: Trade facilitation, Export diversification, International trade agreements, WTO

1 Economic Research Division, World Trade Organization, 1211 Geneva, Switzerland, E-Mail: cosimo.beverelli@wto.org

2 Graduate Institute of International and Development Studies, 1202 Geneva, Switzerland, E-Mail : simon.neumueller@graduateinstitute.ch

3 Economic Research Division, World Trade Organization, 1211 Geneva, Switzerland, E-Mail: robert.teh@wto.org 



\title{
Export Diversification Effects of
}

\section{the WTO Trade Facilitation Agreement*}

\author{
Cosimo Beverelli ${ }^{\dagger} \quad$ Simon Neumueller ${ }^{\ddagger} \quad$ Robert Teh $^{\dagger}$
}

This draft: 16 December 2014

\begin{abstract}
We estimate the effects of trade facilitiation on export diversification, as measured by two extensive margins: the number of products exported by destination and the number of export destinations served by product. To address the issue of causality, we employ an identification strategy whereby only exports of new products, or exports to new destinations, are taken into account when computing the respective margins of trade. We find a positive impact of trade facilitation on the extensive margins of trade. The results are robust to alternative definitions of extensive margins, different sets of controls and various estimation methods. Simulation results suggest substantial extensive margin gains from trade facilitation reform in Sub-Saharan Africa and Latin America and the Caribbean.
\end{abstract}

Keywords: Trade facilitation, Export diversification, International trade agreements, WTO

JEL Classification: F13, F14, F17

\footnotetext{
${ }^{*}$ This is a working paper, and hence it represents research in progress. The opinions expressed in this paper should be attributed to its authors. They are not meant to represent the positions or opinions of the WTO and its Members and are without prejudice to Members' rights and obligations under the WTO. Any errors are attributable to the authors. Without implicating them, we thank Richard Baldwin, Nicolas Berman, Mauro Boffa, Rainer Lanz, Alberto Osnago, Stela Rubínová, Yoto Yotov and participants at the ETSG 2014 (Munich) and seminar participants at the Graduate Institute (Geneva) for helpful discussions and comments. We are also grateful to Evdokia Moïsé for kindly providing the OECD Trade Facilitation Indicators.

${ }^{\dagger}$ Economic Research Division, World Trade Organization. Rue de Lausanne 154, CH-1211, Geneva, Switzerland. E-mail: cosimo.beverelli@wto.org (corresponding author); robert.teh@wto.org.

${ }^{\ddagger}$ Graduate Institute of International and Development Studies, Maison de la Paix, Chemin Eugène-Rigot 2, 1202 Geneva, Switzerland. E-mail: simon.neumueller@graduateinstitute.ch.
} 


\section{Introduction}

Trade economists have for some time now emphasized the need to bring down trade costs, which by many estimates remain quite sizeable. Even for a "representative rich country", Anderson and van Wincoop (2004) have estimated that the ad valorem equivalent of trade costs could be as high as 170\%. As shown by Arvis et al. (2013), customs formalities and trade procedures that result in unnecessary delays or complexities to traders constitute an important component of trade costs. Recognizing this, the WTO 1996 Ministerial Conference in Singapore agreed "to undertake exploratory and analytical work" on this issue. The simplification of the trade procedures has been part of the WTO's negotiating agenda since August 2004. In December 2013, WTO members concluded negotiations on a Trade Facilitation Agreement at the Bali Ministerial Conference. The new agreement will enter into force and become an integral part of the WTO Agreement once two-thirds of WTO members complete their domestic ratification process.

An example of how trade facilitation can simplify trade procedures and make them more transparent can be taken from a country which became a WTO Member in 2013 - the Lao People's Democratic Republic. An online portal for trade has been operative since $2012 .{ }^{1}$ On this website, all trade-related laws, regulations, measures, restrictions, licensing requirements and tariffs are indexed, cross-referenced, and made searchable by commodity code. The website also includes detailed process maps of business procedures for importing and exporting; full listings of national standards for products; procedures for clearing goods at the border; downloadable forms; and e-alerts which traders can customize to receive information.

The importance of achieving success in the WTO negotiations on trade facilitation has been underlined by a fair amount of empirical work. Various approaches for measuring the benefit of a multilateral agreement on trade facilitation have been pursued, including how much it will reduce trade costs, how much trade will increase, as well as the positive impact on jobs and on GDP. One effect that seems not to have been explored in sufficient depth is the effect on export diversification. To the extent that trade and customs procedures act like fixed costs, they prevent exporters from entering new markets or selling a wider array of products. The benefit of export diversification over selling more of the same product or selling more to the same market is the resulting reduction in risk from shocks to international trade. Exporters with diversified export baskets

\footnotetext{
${ }^{1}$ See http://www. laotradeportal.gov.la/index .php?r=site/index.
} 
or destinations are likely to be better insulated from shocks to specific markets or sectors than others. There are various approaches taken in the literature to measure, more or less directly, trade facilitation. Several studies the World Bank's Logistics Performance Index (LPI) and Doing Business indicators as proxies. The LPI is based on a worldwide survey of operators on the ground, providing feedback on the logistics 'friendliness' of the countries in which they operate and those with which they trade. In addition, survey data is supplemented with quantitative data on the performance of key components of the logistics chain in a given country. This includes the quality of trade and transport infrastructure. Doing Business indicators use data on the time and cost (excluding tariffs) associated with exporting and importing a standardized cargo of goods by sea transport. The time and cost necessary to complete every official procedure for exporting and importing the goods are included as well.

The OECD has developed indicators on import, export and transit trade that are closely related, and can be readily mapped on, to the families of measures included in the WTO Trade Facilitation Agreement Information availability, Involvement of the trade community, Advance Rulings, Appeal Procedures, Fees and charges, Formalities, Cooperation, Consularization, Governance and Impartiality and Transit proceedings - see Appendix Table A-1. As explained in Moïsé et al. (2011) and Moïsé and Sorescu (2013), sixteen indicators were constructed based on the relevant provisions of the WTO Trade Facilitation Agreement. The indicators are in turn broken down further into some ninety-seven variables, whose values are drawn from questionnaire replies as well as publicly available data. The variables seek to reflect not only the regulatory framework in the surveyed country but also the state of implementation of the trade facilitation measures. Each of these variables is scored following a 'multiple binary scheme' where the score of two corresponds to the best performance, zero corresponds to the worst performance and a score of one to performance that lies in between.

This paper makes use of the OECD TFIs to estimate the impact of trade facilitation on export diversification, as measured by extensive margins of trade. In the baseline estimations, we consider two types of extensive margins: the number of products (HS sub-headings) by export destination, and the number of export destinations by product. We also consider theory-based extensive margins: the bilateral extensive margin suggested by Hummels and Klenow (2005), and an exporter-product extensive margin that, to the 
best of our knowledge, has not previously been explored in the literature.

While we are not the first to study the extensive-margin effects of trade facilitation, we are the first to do so using the OECD TFIs. Moreover, we add to the existing literature by considering an exporter-product, not only a bilateral dimension of trade margins. A third novel contribution of this paper is the quantification of the effect of implementing trade facilitation under two realistic scenarios: (i) trade facilitation reform that moves countries that are below the median of their region to that benchmark; and (ii) reform that moves countries that are below the global median to that level.

Throughout this study, we focus on trade facilitation in the exporting country. When analyzing the number of destinations by product, this is the only viable option. When analyzing the number of products by destination, we are aware that increases in importers' trade facilitation are likely to have a positive effect. The empirical question of interest, however, concerns the effects of own's trade facilitation for given levels of trade facilitation in destination markets.

The remainder of this paper is organized as follows. The next section provides an overview of the literature on trade facilitation. Section 3 discusses the empirical methodology to estimate the effect of trade facilitation on trade margins. We first define the indicators for the different trade margins used in the empirical analysis. Next, we specify the econometric model. In Section 4, we present the empirical results. Section 5 presents estimations that use alternative measurements of trade margins and of trade facilitation. It also discusses various methodologies employed to test whether the effects are heterogeneous across counties and sectors. Section 6 includes the results of simulations under the two scenarios of convergence to the regional median and convergence to the global median. Section 7 concludes.

\section{Literature}

Trade facilitation has a significant potential to reduce trade costs. This effect has been quantified by a series of empirical studies that follow the methodology of Novy (2013) to infer trade costs from the observed pattern of production and trade across countries. Chen and Novy (2009) estimate that technical barriers to trade, taken as a whole, explain $4.5 \%$ of the variation in trade costs across 11 European Union member countries 
between 1999 and $2003 .^{2}$ Arvis et al. (2013) estimate trade costs in agriculture and manufactured goods in 178 countries for the 1995-2010 period. They find that a one standard deviation improvement in the World Bank's LPI is associated with a trade cost reduction of $0.2-0.5$ standard deviations. Using the OECD TFIs as a measure of trade facilitation, Moïsé et al. (2011) estimate a cost reduction potential of around 10\% of overall trade costs. In a follow-up study, Moïsé and Sorescu (2013) disaggregate the cost-reduction potential across income groups. They estimate this potential to be $14.5 \%$ in low income countries, $15.5 \%$ in lower middle income countries and $13.2 \%$ in upper middle income countries.

Trade facilitation is likely to impact both variable and fixed trade costs. The formalities and requirements of a country's customs have to be met each time a shipment crosses a border. There are, however, also onetime costs such as those incurred by a firm to acquire information on border procedures. The number and complexity of the documents required for clearance can also be seen as a fixed cost. Traders have a one-time cost of learning how to fill in the forms. As the WTO Trade Facilitation Agreement contains provisions requiring countries to publish and make available information on border procedures as well as to decrease and simplify documentation requirements, it should reduce fixed costs and create new trading opportunities. Firms that did not export before may be able to do so now, since their revenues could cover the lower fixed costs of exporting (Melitz, 2003). Trade facilitation can, therefore, both expand existing trade flows (intensive margin effect) and create new trade flows (extensive margin effect).

Empirical evidence on the intensive margin effects is provided by several authors. Iwanow and Kirkpatrick (2009) find that trade facilitation positively contributes to bilateral exports of manufactured products. More recently, Moïsé and Sorescu (2013) estimate a positive effect on bilateral trade flows of bilateral measures of trade facilitation constructed from the OECD TFIs. A related literature highlights the importance of time for trade. Since trade facilitation is likely to reduce the time it takes for products to cross borders, this literature is also relevant in this context. In a recent contribution, Zaki (2014) shows that the time to import (export) is equivalent to a mean ad valorem tax of $34.2 \%(17.6 \%)$ for developing countries. A study by Hummels and Schaur (2013) shows that each day in transit is worth $0.6 \%-2 \%$ of the value of the

\footnotetext{
${ }^{2}$ Their preferred specification explains $80.8 \%$ of the variation in trade costs. $42.8 \%$ is attributable to the 3 -digit industry fixed effects. Of the $38 \%$ that the remaining regressors explain, geography and transport costs alone are responsible for about $25 \%$; policy variables explain $7.6 \%$, with technical barriers to trade (TBTs) being the most important policy factor (4.5\%). TBTs therefore explain $11.8 \%$ of the variation in trade costs not accounted for by unobservable industry characteristics.
} 
good and that time is particularly important for intermediate goods. However, Freund and Rocha (2011) find that when comparing the effects of transit, documentation, and ports and customs delays on trade, the most significant effect comes from inland transit delays. Each additional day that a product is delayed prior to being shipped reduces trade by at least 1 per cent, as found by Djankov et al. (2010). A result which combines the effects of time and costs is obtained by Hausman et al. (2013). In their study, a 1\% reduction in processing costs/time leads to $0.49 \%-0.37 \%$ of increased bilateral trade. There is also firm-level evidence showing the adverse effect of customs delays on trade. Using a sample of Uruguayan firms, Volpe Martincus et al. (2013) show that an increase by two days in the duration of export inspections reduces exports by 16.4\%. Moreover, exports would be $5.9 \%$ larger if all exports could be processed within one day. ${ }^{3}$

Some studies in this literature use econometric results from gravity equations to perform counterfactual analysis. Hoekman and Nicita (2011) simulate the effect of policy convergence by low income countries to the average of middle income countries. The percentage increase in exports (imports) of low income countries that would result from a combined convergence of the Doing Business 'cost of trading' indicator and of the LPI score to the average of middle income countries would be $17 \%(13.5 \%) .{ }^{4}$ Portugal-Perez and Wilson (2012) simulate the effects of improving trade facilitation (broadly encompassing physical infrastructure, information and communications technology, border and transport efficiency as well as business and regulatory environment). Their benchmark is an improvement half-way to the level of the top performing country in the region. The 'ad valorem tariff-cut equivalents' they estimate are heterogeneous across regions, with investment in physical infrastructure generally resulting in the largest trade gains. Hufbauer et al. (2013) perform a thought experiment in which countries lift their trade facilitation halfway to the region's top performer in each category. They estimate an increase in total merchandise exports of developing countries of $\$ 569$ billion (9.9\%) and an increase in total exports of developed countries of $\$ 475$ billion (4.5\%).

The empirical evidence on the extensive margins effects of trade facilitation is more limited than the one on the intensive margins. Nordås et al. (2006) were among the first to show the negative effects of time to export on the probability to export. Dennis and Shepherd (2011) estimate the impact of various Doing Business indicators on the number of products that developing countries export to and import from the

\footnotetext{
${ }^{3}$ See Fernandes and Hillberry (2014) for a similar firm-level study using Albanian custom data.

${ }^{4}$ The LPI index alone has a higher effect than the Doing Business 'cost of trading' indicator. This is because improvements in the LPI also capture improvements in the quality of a country's infrastructure.
} 
European Union. They find that poor trade facilitation has a negative impact on developing country export diversification. Another approach is taken by Feenstra and Ma (2014). They proxy trade facilitation with port efficiency and estimate its impact on export variety, a theory-based measure of the extensive margin. They show a positive and significant effect of port efficiency on export variety. Finally, Persson (2013) distinguishes between the effects of trade facilitation (measured using the number of days needed to export from the World Bank's Doing Business indicators) on homogenous and differentiated products. She finds that trade facilitation has a higher impact on differentiated products. Reducing export transaction costs increases the number of differentiated products by $0.7 \%$ and by $0.4 \%$ for homogenous products.

\section{$3 \quad$ Empirical methodology}

In this section, we define trade margins and trade facilitation indicators. Next, we outline the econometric approach.

\subsection{Trade margins}

We consider the relationship between trade facilitation and two indicators of trade margins: the number of exported products by destination and the number of export destinations by product.

The number of exported products by destination, $n p d_{i j}$, counts how many products country $i$ exports to destination $j$. As a baseline, we define 'products' as HS sub-headings (6 digit HS codes). In the HS 2002 classification that we use, there are 5224 sub-headings. For each $i j$ pair, $n p d_{i j}$ can therefore theoretically range between 0 (no trade) and 5224 (country $i$ exports all products to $j$ ). Panel (a) of Table 1 presents in-sample summary statistics for $n p d_{i j}$. Overall, the variable varies between 0 and 4831 (the latter being $n p d_{U S A-C A N}$ - the number of HS6 sub-headings exported by the United States to Canada). Disaggregating over World Bank regions (and excluding 'Offshore' and 'Industrial' to focus on developing and emerging economies), the mean of $n p d_{i j}$ varies between 43 for Sub-Saharan Africa to 501 for East Asia and Pacific. The incidence of zeros is also highest in Sub-Saharan Africa (32\% of observations) and lowest in Asia (together with Middle East and North Africa). There is, however, considerably less variation across Sub-Saharan African countries than across countries from other regions. 
The number of destinations by product, $n d p_{i k}$, counts how many destinations are served by country $i$ 's exports of product $k$. In this case, too, the baseline definition of 'product' is an HS sub-heading. Panel (b) of Table 1 presents summary statistics for $n d p_{i k}$. Overall, the variable varies between 0 and 169 (the latter being the number of Chinese export destinations of HS sub-heading 392690 - 'Other Articles of Plastics'; HS sub-heading 830140 - 'Other locks of Base Metal'; and HS sub-heading 940320 - 'Other Metal Furniture'). Again, the disaggregation over World Bank regions reveals relatively low scores for Sub-Saharan Africa (with an average of 1 destination served by product), and relatively high scores for Asian countries (with an average of 16 and 9 destinations served by product by East Asia and Pacific and South Asia, respectively). The incidence of zeros is also highest in Sub-Saharan Africa (68\% of observations). The same incidence ranges between $36 \%$ and $51 \%$ for other regions.

Panel (c) of Table 1 presents the summary statistics for $n d p_{i k}$ computed using HS4 trade data, that is, defining 'products' as HS headings. The number of observations and the percentage of zeros are clearly lower than for $n d p_{i k}$ computed from HS6 trade data. Conversely, in the $i j$ sample the sample size is determined by the number of exporting and importing countries, not by the level of sectoral disaggregation.

$<$ Table 1 about here $>$

In the construction of $n p d_{i j}$ and of $n d p_{i k}$, we rely on mirror trade data to the extent possible because import data tend to be more complete than export data. We therefore measure exports of country $i$ in product $k$ using the reported imports of country $j$ in the same product. For the few country-years for which mirror data is not available, we rely on reported export data. ${ }^{5}$

\subsection{Trade Facilitation Indicators}

The sample used for the regressions includes data for 133 countries for which OECD Trade Facilitation Indicators (TFIs) are available. ${ }^{6}$ Table 2 presents summary statistics for the variable TFI. This is the simple average of the country-specific indicators $T F I_{i}^{A}, T F I_{i}^{B}, \ldots, T F I_{i}^{L}{ }^{7}$ The average is unweighted because there

\footnotetext{
${ }^{5}$ Mirror data is not available for the years 2010, 2011 and 2012 for the following countries with TFI information: Antigua and Barbuda, Brunei Darussalam, Cuba, The Gambia, Indonesia, Iran, Kuwait, Mali, Mongolia, Papua New Guinea, Qatar and Suriname.

${ }^{6}$ The full list of countries by World Bank region group, with information on the date of WTO (GATT, where applicable) membership, is available in Appendix Table A-2.

${ }^{7}$ We only have information on indicators A-L.
} 
is no criterion in the WTO Trade Facilitation Agreement or in its previous drafts to rank different indicators in terms of their relevance. Since each sub-indicator ranges between 0 and 2, so does TFI. Among developing and emerging economies, the scores are lowest in Sub-Saharan Africa and highest in Europe and Central Asia. ${ }^{8}$ There is however substantial variation within these regions, and especially within Sub-Saharan Africa (where the best-performing country, Mauritius, has a score of 1.93). The fact that the best performer in Sub-Saharan Africa (the region with the lowest average of TFI) has the highest score in the data suggests that a scenario in which all countries in the region move to the best performer's value is unlikely. We will take this into account in the simulations of Section 6.

$<$ Table 2 about here $>$

\section{$3.3 \quad$ Econometric model}

The TFI data does not vary over time. We therefore estimate cross-sectional regressions for the year 2009. We choose this year for two reasons. First, this is suggested by Moïsé and Sorescu (2013). Second, this allows us to construct measures for $n p d_{i j}$ and $n d p_{i k}$ that are respectively based on new products and new destinations, to address endogeneity concerns (see Section 4$)^{9}$

\subsection{1 ij regressions}

The $i j$ regressions use, as dependent variable, the number of exported products, $n p d_{i j}$. This is a bilateral measure of trade outcomes. It is therefore natural to employ a gravity framework, with the conditional mean of the dependent variable expressed as:

$$
E\left[n p d_{i j} \mid \mathbf{x}_{1 i}, \mathbf{r}_{i}, \mathbf{g}_{i j}, \mathbf{m}_{i j}, \mathbf{d}_{j}\right]=g\left(\mathbf{x}_{1 i}^{\prime} \beta+\mathbf{r}_{i}^{\prime} \theta+\mathbf{g}_{i j}^{\prime} \delta+\mathbf{m}_{i j}^{\prime} \eta+\mathbf{d}_{j}^{\prime} \gamma\right)
$$

In equation (3.1), $g(\cdot)$ is a function; $\mathbf{x}_{1 i}$ is a vector of variables that only vary across exporters $i$ 's; $\mathbf{r}_{i}$ is a vector of exporter-specific region dummies; ${ }^{10} \mathbf{w}_{i j}$ is a vector of standard bilateral gravity variables; $\mathbf{m}_{i j}$ is a vector of multilateral resistance terms, constructed using the methodology outlined in Baier and Bergstrand

\footnotetext{
${ }^{8}$ It is important to note that the latter region does not include industrialized OECD countries - see Table A-2.

${ }^{9}$ The results with all time-varying variables averaged between 2002 and 2010 are very similar to the ones presented here and are available upon request.

${ }^{10}$ World Bank region dummies are included because in the simulations of Section 6 we average results over such regions.
} 
$(2009) ;{ }^{11} \mathbf{d}_{j}$ is a vector of importer $(j)$-specific effects; $\beta, \theta, \delta, \eta$ and $\gamma$ are vectors of coefficients to be estimated. Appendix Table A-3 provides a description of all the variables, including the data sources. ${ }^{12}$

Table 3 presents summary statistics for all control variables.

$<$ Table 3 about here >

As a first step, we estimate a linear fixed effects model by OLS, with the dependent variable in logs, conditioning on importer-specific effects. In this case, $g(\cdot)$ in $(3.1)$ is the identity function. Since the dependent variable is a count variable, a model for count data is more appropriate (Dennis and Shepherd, 2011; Persson, 2013). Accordingly, we also adopt conditional Poisson and Negative Binomial (NB) Maximum Likelihood estimations, with the dependent variable in levels (always conditioning on importer-specific effects). In this case, $g(\cdot)$ in $(3.1)$ is the exponential function. ${ }^{13}$

Appendix Table A-4 presents the in-sample correlations between all variables in the $i j$ sample.

\subsection{2 ik regressions}

The $i k$ regressions use, as dependent variable, the number of export destinations, $n d p_{i k}$. This measure of trade outcomes does not have any bilateral dimension, since it varies by exporting country $i$ and by product $k$. We express the conditional mean of the dependent variable as:

$$
E\left[n d p_{i k} \mid \mathbf{x}_{2 i}, \mathbf{r}_{i}, \mathbf{h}_{k}\right]=g\left(\mathbf{x}_{2 i}^{\prime} \alpha+\mathbf{r}_{i}^{\prime} \phi+\mathbf{h}_{k}^{\prime} \lambda\right)
$$

In equation $(3.2), g(\cdot)$ is a function; $\mathbf{h}_{k}$ is a vector vector of product $(k)$-specific effects; $\alpha, \phi$ and $\lambda$ are vectors of coefficients to be estimated. The vectors $\mathbf{x}_{2 i}$ and $\mathbf{x}_{1 i}$ differ from one another in the following respects. $\mathbf{x}_{2 i}$, but not $\mathbf{x}_{1 i}$, contains the variable Log(remoteness) - a weighted average of partners' ( $j$ 's) world GDP

\footnotetext{
${ }^{11}$ In what Head and Mayer (2013) call the 'structural' representation of the gravity model, the multilateral resistance terms are exporter and importer specific. In cross-section estimation, it is possible to incorporate these terms as importer and exporter fixed effects à la Feenstra (2003). But since our measure of trade facilitation, TFI, is exporter specific, it is impossible to take this approach. Instead, given that the multilateral resistance terms enter multiplicatively in the gravity equation, we incorporate them as a pair or dyadic variable and estimate just one coefficient that measures their combined effect on the number of exported products.

${ }^{12}$ All variables listed in Appendix Table A-3 are self-explanatory, with the exception of the Market Access Trade Restrictiveness Index (TRI). The TRI captures the trade policy distortions imposed by the trading partners on $i$ 's export bundle. It measures the uniform tariff equivalent of the partner country tariff and non-tariff barriers (NTB) that would generate the same level of $i$ 's export value in a given year. The TRI index is constructed using applied tariffs.

${ }^{13}$ Both the Poisson and the NB fixed effect estimators are consistent even in short panels. The NB fixed effect estimator yields more efficient estimation in the presence of overdispersion (Cameron and Trivedi, 2013, p. 357). However, it does not allow for cluster-robust estimation of the variance-covariance matrix. The results are not qualitatively affected by the methodology adopted.
} 
shares, with the inverse distance between $i$ and $j$ as weight (Head and Mayer, 2013). Further, $\mathbf{x}_{1 i}$, but not $\mathbf{x}_{2 i}$, contains the variable $\log ($ weighted $j$ 's TFI) - a weighted average of partners' ( $j$ 's) TFI indicators, with the inverse distance between $i$ and $j$ as weight. ${ }^{14}$

In this case, too, we present a fixed effect linear specification (OLS with dependent variable in logs) as a first step. $g(\cdot)$ in $(3.2)$ is the identity function in this case. We then adopt conditional Poisson and Negative Binomial (NB) Maximum Likelihood estimations with the dependent variable in levels. $g(\cdot)$ in $(3.2)$ is the exponential function in this case. We always condition on product-specific effects.

Appendix Table A-5 presents the in-sample correlations between all variables in the $i k$ sample.

\section{Results}

\section{1 ij regressions}

The results of the $i j$ regressions are in Table 4 . In the OLS regressions, the dependent variable is in logs, while it is in levels in the Poisson and NB regressions. In both cases, however, the coefficients on the explanatory variables in logs can be interpreted as elasticities. ${ }^{15}$

$<$ Table 4 about here >

The baseline results are in columns (1), (2) and (6), respectively for OLS, Poisson and NB regressions. The coefficient on the variable of interest, $\log (\mathrm{TFI})$, is positive and statistically significant in all specifications. In the specification of column (6), the elasticity is 0.305 , implying that a $1 \%$ increase in the average trade facilitation indicator is roughly associated with a $0.3 \%$ increase in the number of HS6 products exported by destination.

The coefficients on the control variables are correctly signed and statistically significant. Although the dependent variable is different, it is useful to compare the distance coefficients with the standard results from gravity studies. As reported in Table of 4 Head and Mayer (2013), the mean of the distance coefficient estimated in 159 papers ranges between -0.93 and -1.1, with a standard deviation of $0.40-0.41$. The distance

\footnotetext{
${ }^{14} \mathrm{We}$ are grateful to Richard Baldwin for suggesting the use of this variable.

${ }^{15}$ See Cameron and Trivedi (2013, p. 346). In the OLS regressions, there are fewer observations because all the observations for which $n p d_{i j}=0$ are dropped. The Poisson and NB regressions drop all observations with $n p d_{i j}=0$ across all destinations, because they do not contribute to the conditional likelihoods.
} 
elasticity we obtain is in line with Table 4 of Head and Mayer (2013) for the OLS estimation. In the Poisson and NB model it is lower, but it is a well-established fact in the literature that the distance coefficient is lower when using count-data models. Moreover, our result is very similar to the one obtained by Persson (2013), which is the most comparable study to ours.

We see two possible concerns with the baseline estimations. First, and foremost, we cannot exclude reverse causation, that is the possibility that trade outcomes affect the incentives to invest in trade facilitation, and consequently the trade facilitation scores. In the spirit of Freund and Rocha (2011) and Portugal-Perez and Wilson (2012), we address possible reverse causality using only 'new products' (HS sub-headings) in the construction of the dependent variable. We proceed as follows: when computing how many products country $i$ exported to country $j$ in 2009, we only include the subset of products for which: (i) there were no exports from $i$ to $j$ (zero or missing) recorded in any of the years between 2002 and 2007; and (ii) there were positive exports from $i$ to $j$ recorded in at least one year between 2008 and 2010. Since $n p d_{i j}$ is, in this case, the count of new HS6 products that were not traded before 2008, it is less likely to be endogenous to trade facilitation than the indicator calculated using the set of products traded in 2009.

The use of 'new products' has an additional advantage. We do not necessarily exclude products that dropped from a country's bilateral export basket during the big trade collapse of 2009. As long as a product that was not exported in any year between 2002 and 2007 started to be exported in any year before 2008 and 2010, it counts for the construction of $n p d_{i j}$.

The results are in columns (3) and (7) of Table 4. The coefficients are slightly lower than in the baseline regressions (indicating the possibility of a small downward bias induced by reverse causality), but still positive and statistically significant.

The second possible concern with the baseline estimations of Table 4 relates to the measurement of trade facilitation. So far, we have used TFI - the unweighted average of the country-specific OECD Trade Facilitation Indicators. As an alternative, we have created a trade facilitation indicator based on Principal Component Analysis (PCA). The results of Poisson estimations are in columns (4) and (5). They are very similar to the corresponding results of columns (2) and (3). ${ }^{16}$

\footnotetext{
${ }^{16}$ To save space, we do not report NB results with TFI computed using Principal Component Analysis (PCA). They are similar to the results in columns (6) and (7) and available upon request.
} 


\section{2 ik regressions}

The results of $i k$ regressions are in Table 5 . The structure of the table is similar to that of Table 4 .

$<$ Table 5 about here $>$

The coefficient on $\log (\mathrm{TFI})$ is positive and significant in all specifications. The estimated elasticity in column (6) is 0.383 . This implies that a $1 \%$ increase in the average trade facilitation indicator is roughly associated with a $0.38 \%$ increase in the number of destinations to which an HS6 product is exported.

In columns (3) and (7) we address possible reverse causality concerns using only 'new destinations' in the computation of the dependent variable. The procedure is very similar in spirit to the one described above in the case of $i j$ regressions. When computing how many destination countries were served by country $i$ in exporting product $k$ in 2009, we only include the subset of destinations for which: (i) there were no exports of product $k$ (zero or missing) recorded in any of the years between 2002 and 2007; (ii) there were positive exports of product $k$ recorded in at least one year between 2008 and 2010. In this case, therefore, $n d p_{i k}$ becomes the count of new destinations that were not served before 2008 .

Also in this case, the use of 'new destinations' has the additional advantage that we do not necessarily exclude destinations that ceased to be served by country $i$ in sector $k$ during the big trade collapse of 2009. As long as a destination that was not served in any year between 2002 and 2007 started to get served in any year before 2008 and 2010, it counts for the construction of $n d p_{i k}$.

In the regressions with new destinations, the estimated coefficient on $\log (\mathrm{TFI})$ is slightly larger than the baseline coefficient, both in the Poisson and in the NB specifications.

In columns (5) and (5) we present the results of the regressions that use a measure of TFI based on Principal Component Analysis, rather than the simple mean across indicators. Again, the results do not change significantly. ${ }^{17}$

\footnotetext{
${ }^{17} \mathrm{NB}$ results are available upon request.
} 


\section{Robustness}

\subsection{Trade margins based on HS4 trade data}

The results of $i j$ and $i k$ regressions using trade margins based on HS4 trade data are in Table 6 . For ij regressions, Poisson and NB baseline results should be compared with columns (2) and (6) of Table 4, respectively. Results with new products (columns (2) and (4)) shoud be compared with columns (3) and (7) of Table 4. For $i k$ regressions, columns (5) and (7) should be compared with columns (2) and (6) of Table 5, while columns (6) and (8) should be compared with columns (3) and (7) of Table 5. All coefficients on $\log (\mathrm{TFI})$ are quite similar across comparable regressions. This implies that our results are not affected by the level of product disaggregation of the data.

$<$ Table 6 about here $>$

\subsection{Hummel-Klenow trade margins}

In this section, we present econometric estimates using the theory-based 'Hummels-Klenow extensive margins' as dependent variables. In the regressions with country pairs, we use the following variable, directly from Hummels and Klenow (2005):

$$
e m_{i j}=\frac{\sum_{k \in K_{i j}} X_{w j k}}{\sum_{k \in K} X_{w j k}}
$$

In equation (5.1), $K_{i j}$ is the set of goods which country $i$ exports to country $j$; $w$ is the reference country that has positive exports to $j$ in all products $k$ (in the empirical implementation, it is the rest of the world); $K$ is the set of all products; $X_{w j k}$ are the exports of country $w$ to country $j$ in product $k$. $e m_{i j}$ is therefore the share of those exports to $j$ only in goods $k$ that country $i$ exports in total exports to country $j$.

In the regressions with country-product observations, we construct a similar measure (not previously used in the reviewed literature):

$$
e m_{i k}=\frac{\sum_{j \in J_{i k}} X_{w j k}}{\sum_{j \in J} X_{w j k}}
$$

In equation (5.2), $J_{i k}$ is the set of destinations to which country $i$ exports product $k ; w$ is the reference country that has positive exports of $k$ to all destinations $j$ (in the empirical implementation, it is the rest 
of the world); $J$ is the set of all destinations; $X_{w j k}$ are - as in equation (5.1) - the exports of country $w$ to country $j$ in product $k . e m_{i k}$ is therefore the share of exports of $k$ only to destinations $j$ that country $i$ exports to in total exports of product $k$ to all destinations. ${ }^{18}$

The summary statistics for the Hummels-Klenow extensive margins $e m_{i j}$ and $e m_{i k}$ are in Appendix Table A-6. In the developing world, Hummels-Klenow extensive margins, and therefore export diversification, are lowest in Sub-Saharan Africa and highest in East Asia and Pacific. From a qualitative standpoint, these descriptive statistics are in line with the ones presented in Table 1 for $n p d_{i j}$ and $n d p_{i k}$. In fact, the sample correlation between $n p d_{i j}$ and $e m_{i j}$ is equal to 0.89 , while the sample correlation between $n d p_{i k}$ and $e m_{i k}$ is equal to $0.83 .^{19}$

Table 7 present the results of $i j$ and $i k$ regressions using, as dependent variable, the Hummels-Klenow extensive margins $e m_{i j}$ and $e m_{i k}$, respectively. The dependent variable ranges between zero and one. As suggested by Baum (2008), we use a Generalized Linear Model (GLM) with a logit transformation of the response variable and the binomial distribution. Odd-numbered columns present baseline results, in which the respective trade margin is calculated using trade data from 2009. In even-numbered columns we address concerns related to reverse causality and construct the dependent variable using only the subset of new products (in the case of $e m_{i j}$ ) or new destinations (in the case of $e m_{i k}$ ). ${ }^{20}$

$<$ Table 7 about here $>$

In the $i j$ regressions, controlling for country characteristics, partner $j$ dummies, region dummies and bilateral control variables, the coefficient on $\log (\mathrm{TFI})$ is positive, but it loses statistical significance in column (2). In the $i k$ regressions, where we control for country characteristics, product $k$ dummies and region dummies, only the coefficient on $\log (\mathrm{TFI})$ in column (3) is correctly signed and statistically significant. When we use the definition of the Hummels-Klenow extensive margin $e m_{i k}$ based on new destinations, this coefficient turns negative and statistically significant. There is no easy way to explain this counter-intuitive result. It should be mentioned, however, that the coefficient on $\log (\mathrm{TFI})$ is correctly signed and statistically significant if we perform the same regression of column (4) of Table 7 using HS4 headings in the construction $e m_{i k}$.

\footnotetext{
${ }^{18}$ We use the Stata module developed by Ansari (2013) to compute $e m_{i j}$ and $e m_{i k}$.

${ }^{19}$ Sample correlations computed from columns (1) and (3) of Table 7, respectively.

${ }^{20}$ See Section 4.1 for details on the procedure.
} 


\subsection{World Bank Doing Business indicators}

Following, among others, Hoekman and Nicita (2011) and Dennis and Shepherd (2011), we also perform regressions that use, as proxies for trade facilitation, the 'Trading across borders' indicators of the World Bank Doing Business database. In this database, there are three indicators relevant for our purposes: number of documents to export; ${ }^{21}$ number of days required to export; ${ }^{22}$ and cost to export (US\$ per container). ${ }^{23}$

To increase comparability with the results that use the OECD TFIs, we transform these variables as follows.

First, we compute their inverse. Then, we rescale them between 0 (least facilitation) and 2 (most facilitation). Appendix Table A-7 presents the in-sample correlations among these variables, and the correlations between these variables and TFI.

The results are in Table 8. All the coefficients on DB docs, DB cost and DB time are consistently positive across all specifications, both in the $i j$ and in the $i k$ regressions. It should be noted that $i j$ regressions use the same set of explanatory variables as Table 4 and $i k$ regressions use the same set of explanatory variables as Table 5 .

$<$ Table 8 about here $>$

\subsection{The elusive quest for heterogeneous effects}

Beyond the central results of Section 4, we also investigate possible heterogeneity in the impact of trade facilitation on the extensive margins of trade. An important potential source of heterogeneity is between country pairs that have a PTA in place and country pairs that do not have one. There is ample evidence that most PTAs include trade facilitation provisions (see for instance Neufeld, 2014). Maur (2011) argues that in areas such as product standards and technical regulations, trade facilitation through policies such as harmonization between PTA members has the potential to introduce discrimination vis-à-vis excluded countries. Conversely, aspects of trade facilitation such as transparency and simplification of rules and procedures (the narrow definition of trade facilitation that we use in this paper and that is reflected in the

\footnotetext{
${ }^{21}$ The total number of documents required per shipment to export goods. Documents required for clearance by government ministries, customs authorities, port and container terminal authorities, health and technical control agencies and banks are taken into account.

${ }^{22}$ The time necessary to comply with all procedures required to export goods.

${ }^{23}$ The cost associated with all procedures required to export goods. It includes the costs for documents, administrative fees for customs clearance and technical control, customs broker fees, terminal handling charges and inland transport.
} 
OECD TFIs), should be non-discriminatory in nature and therefore benefit all trading partners equally. If this is the case, one should not expect any heterogeneous effect of exporter's trade facilitation on the extensive margin of bilateral trade across importers with a PTA with the exporter and importers without.

To test this prediction, we augment the $i j$ regressions with an interaction term between the PTA dummy and $\log (\mathrm{TFI})$. We do not obtain any consistent pattern in the results. In most regressions, the marginal effect when the PTA dummy is equal to one is not statistically different from the marginal effect when the PTA dummy is equal to zero. The evidence that an exporting country's trade facilitation does not have a higher impact on the bilateral extensive margin with importers with which it has a PTA provides indirect support for the idea that the trade facilitation provisions captured by the OECD TFIs (and disciplined by the WTO Trade Facilitation Agreement) are non-discriminatory.

In a similar way, we investigate the effects of having a common border (without any significant result) or a common language. Although obtaining significant results in a few instances, indicating that trade facilitation is even more important if the trading partners have different languages, we do not find consistent results across all specifications. ${ }^{24}$

One might be concerned that our results might be driven by developed countries only. To rule this out, we split the $i j$ sample in four subsamples: DD (both exporter $i$ and importer $j$ are developed) ${ }^{25}$ DG $(i$ is developed, $j$ is developing); GD ( $i$ is developing, $j$ is developed); GG (both $i$ and $j$ are developing). As shown in Table 9, each of these subsample covers approximately one quarter of the $i j$ dataset. Although varying in magnitude across different specifications, the results are qualitatively similar across sub-samples. We therefore reject the hypothesis that our results are driven by developed countries.

$<$ Table 9 about here $>$

We further check whether the effect of trade facilitation on the extensive margins differs between final and intermediate products. Yi (2003) developes a model in which trade costs hamper vertically-specialized trade (i.e. trade along supply chains) relatively more than trade in final products. ${ }^{26}$ Martinez-Zarzoso and Márquez-

\footnotetext{
${ }^{24}$ The results are available upon request.

${ }^{25}$ We consider 'developed' countries classified by the World Bank as High-income or Upper-middle-income economies. Lowincome and Lower-middle-income economies are considered 'developing'.

${ }^{26}$ Yi's model shows the magnifying trade effects of tariff reductions when vertically specialized goods cross multiple borders while they are being produced. He argues that reductions in transportation costs and trade reforms more general than tariff liberalization also have a magnifying effect on trade. Ferrantino (2012) makes the link with trade facilitation explicit. He argues
} 
Ramos (2008) show that improvements in the Doing Business indicators 'Number of days' and 'Document required' to export/import have a relatively larger effect on technology-intensive goods and on differentiated products, as opposed to homogeneous ones. Marti et al. (2014) argue that improvements in the LPI have an effect which is larger for goods that are relatively more complex to transport. In a more direct test of Yi's hypothesis, Saslavsky and Shepherd (2012) show that trade in parts and components - which they assume takes place largely within production networks - is more sensitive to improvements in logistics performance than trade in final goods. These papers focus on the intensive margin of trade (bilateral trade value in a gravity framework). As discussed in Section 2, Persson (2013) applies similar ideas to the extensive margins of trade. She does not explicitly consider trade in intermediate products as her focus is on product differentiation. She finds that trade facilitation has a higher extensive margin impact on trade in differentiated products than on trade in homogenous products.

In the spirit of this literature, we test for heterogeneous effects on the extensive margins of trade between intermediate and non-intermediate and products. We use two alternative definitions of intermediate products, a narrow one and a broad one. The narrow definition, adopted by WTO (2011), includes the HS sub-headings corresponding to codes 42 and 53 of the Broad Economic Categories (BEC) classification, supplemented with unfinished textile products in HS chapters 50-63. The broad definition includes the HS sub-headings corresponding to the intermediate goods of the BEC classification.

As a first step, we estimate the $i j$ regressions in two sub-samples: one in which the dependent variable is computed across the subset of intermediate products; one in which the dependent variable is computed across the subset of all other products. We are not able to find any significant difference between estimated coefficients across these specifications. To test this result further, in the $i k$ sample we augment the regressions with an interaction term between a dummy equal to one if the product is intermediate and the $\log (\mathrm{TFI})$ variable. We do not find the coefficient of this interaction term to be significant in most specifications. ${ }^{27}$ This leads us to conclude that the effect of trade facilitation on the extensive margin does not differ between intermediate and final products.

that NTMs and trade facilitation can be compared using a common metric. Efforts to reduce NTMs and efforts to increase trade facilitation should both have larger effects on trade in complex supply chains that on trade in simple supply chains. See also U.S. Chamber of Commerce (2014) and UNECA (2013) for less formal expositions, respectively by the business community and by an international organization, of the idea that trade facilitation should matter most for intermediate goods trade.

${ }^{27}$ The results are available upon request. 


\section{Simulation results}

In this section, we present the results of counterfactual analysis aimed at providing insights into the economic significance of our results. We estimate the percentage increase in the number of export destinations and in the number of exported products under two different scenarios. As shown in the 'sd' column of Table 2, there is wide variation in TFI scores across countries belonging to the same geographical region. This suggests that a scenario involving convergence to the top regional performer would be very unrealistic. Such a scenario is, therefore, discarded a priori. Instead we consider two realistic scenarios. The first scenario is one in which each country with a TFI score below the median of the geographical region it belongs to increases its TFI to the regional median. The second scenario considers an increase to the global median.

It is important to note that results of counterfactual analysis have to be taken cautiously. First, because they are only as good as the underlying econometric model. Although we have taken care in addressing omitted variable and reverse causality biases, we cannot control for every possible country-specific variable correlated with trade facilitation and we cannot completely exclude the endogenous co-determination of trade outcomes and trade facilitation infrastructure. Second, the counter-factual analysis does not take into account that regional (global) median values would be affected by changes in trade facilitation occurring in all countries in the region (world).

With these caveats in mind, the baseline results, grouped by region, are presented in Table 10 for $i j$ regressions and Table 11 for $i k$ regressions. To remain on the conservative side, we have chosen to base the simulations on the Negative Binomial (NB) results, which generally yield smaller estimated coefficients on Log(TFI) than the coefficients of Poisson regressions. ${ }^{28}$

For ease of interpretation, it is useful to keep in mind that the entries in tables 10 and 11 represent the percentage change in the variable of interest (respectively, $n p d_{i j}$ and $n d p_{i k}$ ) that, based on the estimated regression coefficients, are predicted if country $i$ moves from below the regional (global) median to the relevant median. The results are then averaged across regions. All countries at, or above, the relevant median are dropped from the calculation of the regional average percentage increase in the trade margin. If, say, in a given region there are 16 countries, 8 of which are below the regional median and 15 below the global median,

\footnotetext{
${ }^{28}$ The simulation results using the coefficients from Poisson regressions are available upon request.
} 
the results under the regional median scenario are averaged over the 8 bottom countries in terms of TFI, while the results under the global median scenario are averaged over all countries with the exclusion of the top regional performer.

Tables 10 and 11 have two panels each. In the upper panel, we present results based on regressions using HS6 trade data. In the lower panel, we present results based on regressions using HS4 trade data. We use both the 'baseline' NB and the NB specifications with new products and new destinations. Since the estimates obtained in the latter specifications address the issue of reverse causality, we take them as our preferred results. We therefore discuss only the results of even-numbered columns.

$<$ Tables 10 and 11 about here >

As expected, the estimated gains in terms of number of products exported by destination $\left(n p d_{i j}\right)$ are quite similar in panels (a) and (b) of Table 10 (the correlation between $n p d_{i j}$ computed from HS6 trade data and $n p d_{i j}$ computed from HS4 trade data is 0.98), but also in panels (a) and (b) of Table 11. The percentage gains range from $4.1 \%$ in the case of South Asia (HS4 data, both scenarios) to $15.7 \%$ in the case of Sub-Saharan Africa (HS6 data, global median scenario). It is apparent from the table that the gains are largest in two regions, namely Sub-Saharan Africa and Latin America and the Caribbean.

In the case of the number of export destinations by product $\left(n d p_{i k}\right)$, the estimated gains range from $7.2 \%$ for South Asia (regional median scenario, HS4 regressions) to 27.9\% for Sub-Saharan Africa (global median scenario, HS6 regressions). In this case, too, the gains are largest in Sub-Saharan Africa and Latin America and the Caribbean.

\section{Conclusions}

This is the first paper to focus exclusively on, and to provide detailed estimates of, the prospective effect of the WTO Trade Facilitation Agreement on export diversification, as measured by the extensive margins of trade. We do so by using direct measures of trade facilitation that map into the obligations of the agreement, namely, the OECD Trade Facilitation Indicators. We explore a variety of measures of the extensive margins of trade - the number of products a country exports to a given destination $\left(n p d_{i j}\right)$, the number of destinations 
to which a country exports a given product $\left(n d p_{i k}\right)$, the Hummels-Klenow measure of the bilateral extensive margin $\left(e m_{i j}\right)$ and a similar measure of the country-product extensive margin $\left(e m_{i k}\right)$ that has not previously been explored in the literature.

The estimation results are convincing, with the coefficient on the trade facilitation variable being positive and statistically significant across almost all specifications. Using these estimates, we simulate the impact of implementing the agreement on developing countries' extensive margin of trade. Implementation of the agreement is measured using two alternative realistic scenarios - convergence to the regional median and convergence to the global median. Developing countries are likely to experience a substantial increase in the number of products exported and of destination markets. For Sub-Saharan African countries, our simulations suggest they could see an increase of up to $15.7 \%$ in the number of products exported by destination and an increase of up to $27.9 \%$ in the number of export destinations by product. For countries in Latin America and the Caribbean, our simulations suggest they could see an increase of up to $12.2 \%$ in the number of products exported by destination and an increase of up to $21.7 \%$ in the number of export destinations by product. For the reasons outlined in Section 6, these numbers have to be treated with caution. Nonetheless, they imply potentially sizeable impacts of the Trade Faciliation Agreement on extensive margins of export, and therefore on export diversification.

We see three potential avenues for further research. First, the analysis could be conducted at the level of specific TFI indicators. Such analysis would shed light on which provisions of the WTO Trade Facilitation Agreement have the most effect on the extensive margins of trade. Second, simulations could be based on actual implementation schedules which will have to be notified by WTO members. Third, research should focus on the effect of trade facilitation on trade margins computed from firm-level, as opposed to sector-level data.

Finally, we emphasize that we make no claim about the welfare effects of implementing the WTO Trade Facilitation Agreement. This would require us to estimate not only the benefits but also the costs of implementing the agreement. Notwithstanding this qualification, we know from the available literature that the costs of implementation of trade facilitation initiatives are relatively small (OECD, 2009; UNECA, 2013). At the same time, our estimations do not capture several other potential benefits of the agreement. A proper 
welfare analysis would also factor in the value of locking in commitments in a multilateral agreement and other positive spillovers, such as, for instance, the reduction in the extent of rent-seeking behaviour or the environmental benefit of lower fuel consumption from shorter waiting times at the border. These topics need to be investigated further to get a more comprehensive understanding of the effects of the WTO Trade Facilitation Agreement. 


\section{References}

Anderson, J. E., and E. van Wincoop, 2004, "Trade Costs," Journal of Economic Literature, 42, 691-751.

Ansari, M. R., 2013, "HUMMELS: Stata module to compute intensive and extensive trade margins," Statistical Software Components, Boston College Department of Economics.

Arvis, J.-F., Y. Duval, B. Shepherd, and C. Utoktham, 2013, "Trade costs in the developing world: 19952010," World Bank Policy Research Working Paper No. 6309.

Baier, S. L., and J. H. Bergstrand, 2009, "Bonus vetus OLS: A simple method for approximating international trade-cost effects using the gravity equation," Journal of International Economics, 77, 77-85.

Baum, C. F., 2008, "Stata tip 63: Modeling proportions," The Stata Journal, 8, 299-303.

Cameron, A. C., and P. K. Trivedi, 2013, Regression analysis of count data, Econometric Society monograph No. 53, Cambridge University Press, New York, second edn.

Chen, N., and D. Novy, 2009, "International Trade Integration: A Disaggregated Approach," CEP Discussion Paper No. 0908, Centre for Economic Performance, LSE.

Dennis, A., and B. Shepherd, 2011, "Trade Facilitation and Export Diversification," The World Economy, $34,101-122$.

Djankov, S., C. Freund, and C. S. Pham, 2010, "Trading on time," The Review of Economics and Statistics, $92,166-173$.

Feenstra, R. C., 2003, Advanced international trade: theory and evidence, Princeton University Press, Princeton, NJ.

Feenstra, R. C., and H. Ma, 2014, "Trade Facilitation and the Extensive Margin of Exports," Japanese Economic Review, 65, 158-177.

Fernandes, A. M., and R. Hillberry, 2014, "Customs reform and trade growth: Evidence from Albania," Presented at the Third Annual WTO/IMF/World Bank Trade Workshop, Washington, D.C., 7 November. 
Ferrantino, M. J., 2012, "Using Supply Chain Analysis to Examine the Costs of Non-Tariff Measures (NTMs) and the Benefits of Trade Facilitation," WTO Staff Working Paper No. ERSD-2012-02.

Freund, C., and N. Rocha, 2011, "What Constrains Africa's Exports?," World Bank Economic Review, 25, 361-386.

Hausman, W. H., H. L. Lee, and U. Subramanian, 2013, "The Impact of Logistics Performance on Trade," Production and Operations Management, 22, 236-252.

Head, K., and T. Mayer, 2013, "Gravity equations: Workhorse, toolkit, and cookbook," in E. Helpman, K. Rogoff, and G. Gopinath (ed.), Handbook of International Economics, 4: 131-195, Elsevier, Oxford and Amsterdam.

Head, K., T. Mayer, and J. Ries, 2010, "The erosion of colonial trade linkages after independence," Journal of International Economics, 81, 1-14.

Hoekman, B., and A. Nicita, 2011, "Trade Policy, Trade Costs, and Developing Country Trade," World Development, 39, 2069-2079.

Hufbauer, G., J. Schott, C. Cimino, and J. Muir, 2013, "Payoff from the World trade agenda," Report to the ICC Research Foundation, Peterson Institute for International Economics.

Hummels, D., and P. J. Klenow, 2005, "The Variety and Quality of a Nation's Exports," American Economic Review, 95, 704-723.

Hummels, D. L., and G. Schaur, 2013, "Time as a Trade Barrier," American Economic Review, 103, 29352959.

Iwanow, T., and C. Kirkpatrick, 2009, "Trade Facilitation and Manufactured Exports: Is Africa Different?," World Development, 37, 1039 - 1050.

Kee, H. L., A. Nicita, and M. Olarreaga, 2009, "Estimating Trade Restrictiveness Indices," Economic Journal, $119,172-199$. 
Marti, L., R. Puertas, and L. García, 2014, "Relevance of trade facilitation in emerging countries' exports," The Journal of International Trade \&3 Economic Development, 23, 202-222.

Martinez-Zarzoso, I., and L. Márquez-Ramos, 2008, "The Effect of Trade Facilitation on Sectoral Trade," The B.E. Journal of Economic Analysis 83 Policy, 8, 1-46.

Maur, J. C., 2011, "Trade facilitation," in J.-P. Chauffour, and J. C. Maur (ed.), Preferential trade Agreement Policies for Development, The World Bank, Washington, D.C.

Melitz, M. J., 2003, "The Impact of Trade on Intra-Industry Reallocations and Aggregate Industry Productivity," Econometrica, 71, 1695-1725.

Moïsé, E., T. Orliac, and P. Minor, 2011, "Trade Facilitation Indicators: The Impact on Trade Costs," OECD Trade Policy Paper No. 118.

Moïsé, E., and S. Sorescu, 2013, "Trade Facilitation Indicators: The Potential Impact of Trade Facilitation on Developing Countries' Trade," OECD Trade Policy Paper No. 144.

Neufeld, N., 2014, "Trade Facilitation Provisions in Regional Trade Agreements - Traits and Trends," WTO Staff Working Paper No. ERSD-2014-01.

Nordås, H. K., E. Pinali, and M. Geloso Grosso, 2006, "Logistics and Time as a Trade Barrier," OECD Trade Policy Paper No. 35.

Novy, D., 2013, "Gravity Redux: Measuring International Trade Costs With Panel Data," Economic Inquiry, $51,101-121$.

Organization for Economic Co-operation and Development (OECD), 2009, Overcoming Border Bottlenecks: The Costs and Benefits of Trade Facilitation, OECD, Paris.

Persson, M., 2013, "Trade facilitation and the extensive margin," The Journal of International Trade 83 Economic Development, 22, 658-693.

Portugal-Perez, A., and J. S. Wilson, 2012, "Export Performance and Trade Facilitation Reform: Hard and Soft Infrastructure," World Development, 40, 1295 - 1307. 
Saslavsky, D., and B. Shepherd, 2012, "Facilitating international production networks : the role of trade logistics," Policy Research Working Paper No. 6224, The World Bank.

United Nations Economic Commission for Africa (UNECA), 2013, Trade Facilitation from an African Perspective, Economic Commission for Africa, Addis Ababa, Ethiopia.

U.S. Chamber of Commerce, 2014, "Global Supply Chain, Customs and Trade Facilitation," available at https://www.uschamber.com/issue-brief/ global-supply-chain-customs-and-trade-facilitation. [Accessed 6 October 2014].

Volpe Martincus, C., J. Carballo, and A. Graziano, 2013, "Customs as Doorkeepers: What Are Their Effects on International Trade?," available at http://www.usitc.gov/research_and_analysis/documents/ Customs_as-Doorkeepers-What_Are_Their_Effects_on_International_Trade.pdf.

World Trade Organization (WTO), 2011, World Trade Report 2011. The WTO and preferential trade agreements: From co-existence to coherence, World Trade Organization, Geneva.

Yi, K.-M., 2003, "Can Vertical Specialization Explain the Growth of World Trade?," Journal of Political Economy, 111, pp. 52-102.

Zaki, C., 2014, "An empirical assessment of the trade facilitation initiative: econometric evidence and global economic effects," World Trade Review, 13, 103-130. 


\section{Tables}

Table 1: Summary statistics of $n p d i j$ and $n d p_{i k}$, by World Bank region

Panel (a): $n p d_{i j}$

\begin{tabular}{lcccccccc}
\hline \hline World Bank region & mean & median & sd & min & max & N & zeros & \% zeros \\
\hline Sub-Saharan Africa & 43 & 3 & 200.43 & 0 & 4525 & 5157 & 1638 & $32 \%$ \\
East Asia and Pacific & 501 & 111 & 793.09 & 0 & 4224 & 2254 & 382 & $17 \%$ \\
Europe and Central Asia & 216 & 18 & 475.86 & 0 & 3788 & 3862 & 849 & $22 \%$ \\
Latin America and Caribbean & 115 & 9 & 321.68 & 0 & 3429 & 3864 & 870 & $23 \%$ \\
Middle East and North Africa & 121 & 20 & 280.25 & 0 & 3443 & 1772 & 300 & $17 \%$ \\
South Asia & 283 & 53 & 548.43 & 0 & 3740 & 967 & 162 & $17 \%$ \\
Offshore & 14 & 2 & 64.62 & 0 & 780 & 161 & 55 & $34 \%$ \\
Industrial & 946 & 489 & 1088.38 & 0 & 4831 & 3220 & 72 & $2 \%$ \\
Whole sample & 290 & 18 & 655.92 & 0 & 4831 & 21257 & 4329 & $20 \%$ \\
\hline \hline
\end{tabular}

Descriptive statistics computed from the sample of column (6) of Table 4 and based on HS6 trade data

Panel (b): $n d p_{i k}$ (HS6 trade data)

\begin{tabular}{lcccccccc}
\hline \hline World Bank region & mean & median & $\mathrm{sd}$ & $\min$ & $\max$ & $\mathrm{N}$ & zeros & \% zeros \\
\hline Sub-Saharan Africa & 1 & 0 & 4.87 & 0 & 128 & 167008 & 114129 & $68 \%$ \\
East Asia and Pacific & 16 & 2 & 29.46 & 0 & 169 & 73066 & 26561 & $36 \%$ \\
Europe and Central Asia & 7 & 1 & 13.49 & 0 & 135 & 125256 & 49152 & $39 \%$ \\
Latin America and Caribbean & 4 & 1 & 9.12 & 0 & 137 & 125256 & 62326 & $50 \%$ \\
Middle East and North Africa & 4 & 1 & 9.28 & 0 & 122 & 57409 & 28086 & $49 \%$ \\
South Asia & 9 & 0 & 20.40 & 0 & 166 & 31314 & 16040 & $51 \%$ \\
Offshore & 0 & 0 & 1.42 & 0 & 63 & 5219 & 3972 & $76 \%$ \\
Industrial & 30 & 16 & 34.41 & 0 & 167 & 104380 & 12544 & $12 \%$ \\
Whole sample & 9 & 1 & 21.16 & 0 & 169 & 688908 & 312810 & $45 \%$ \\
\hline \hline
\end{tabular}

Descriptive statistics computed from the sample of column (6) of Table 5

Panel (c): $n d p_{i k}$ (HS4 trade data)

\begin{tabular}{lcccccccc}
\hline \hline World Bank region & mean & median & sd & min & max & N & zeros & \% zeros \\
\hline Sub-Saharan Africa & 3 & 1 & 8.87 & 0 & 138 & 39808 & 18523 & $47 \%$ \\
East Asia and Pacific & 28 & 8 & 40.43 & 0 & 174 & 17416 & 4039 & $23 \%$ \\
Europe and Central Asia & 13 & 4 & 20.71 & 0 & 146 & 29856 & 6567 & $22 \%$ \\
Latin America and Caribbean & 8 & 2 & 15.22 & 0 & 141 & 29856 & 8677 & $29 \%$ \\
Middle East and North Africa & 10 & 3 & 16.74 & 0 & 137 & 13684 & 3598 & $26 \%$ \\
South Asia & 17 & 2 & 31.44 & 0 & 169 & 7464 & 2519 & $34 \%$ \\
Offshore & 1 & 0 & 3.00 & 0 & 67 & 1244 & 672 & $54 \%$ \\
Industrial & 50 & 38 & 44.34 & 0 & 173 & 24880 & 1246 & $5 \%$ \\
Whole sample & 17 & 3 & 30.41 & 0 & 174 & 164208 & 45841 & $28 \%$ \\
\hline \hline
\end{tabular}

Descriptive statistics computed from the sample of column (7) of Table 6 
Table 2: Summary statistics, TFI, by World Bank region

\begin{tabular}{lcccccc}
\hline \hline World Bank region & mean & median & sd & min & max & $\mathrm{N}$ \\
\hline Sub-Saharan Africa & 1.04 & 1.01 & 0.35 & 0.22 & 1.93 & 5157 \\
East Asia and Pacific & 1.32 & 1.33 & 0.27 & 0.81 & 1.81 & 2254 \\
Europe and Central Asia & 1.39 & 1.37 & 0.28 & 0.77 & 1.91 & 3862 \\
Latin America and Caribbean & 1.20 & 1.28 & 0.32 & 0.45 & 1.65 & 3864 \\
Middle East and North Africa & 1.21 & 1.15 & 0.27 & 0.83 & 1.65 & 1772 \\
South Asia & 1.23 & 1.21 & 0.16 & 1.01 & 1.38 & 967 \\
Offshore & 1.20 & 1.20 & 0.00 & 1.20 & 1.20 & 161 \\
Industrial & 1.50 & 1.54 & 0.18 & 1.13 & 1.86 & 3220 \\
Whole sample & 1.26 & 1.29 & 0.33 & 0.22 & 1.93 & 21257 \\
\hline \hline
\end{tabular}

Descriptive statistics computed from the sample of column (6) of Table 4

Table 3: Summary statistics, control variables

\begin{tabular}{lccccc}
\hline \hline Variable & mean & median & sd & min & max \\
\hline Log(pcGDP) & 8.49 & 8.51 & 1.46 & 5.38 & 11.27 \\
Log(market access) & -2.43 & -2.38 & 0.76 & -5.37 & -1.15 \\
Number of PTAs & 40.53 & 41.00 & 25.98 & 0 & 88 \\
Log(area) & 11.90 & 12.01 & 2.11 & 5.76 & 16.65 \\
Landlocked & 0.21 & 0.00 & 0.41 & 0 & 1 \\
Log(weighted j's TFI) & 0.26 & 0.26 & 0.06 & 0.01 & 0.35 \\
Log(remoteness) & 8.50 & 8.62 & 0.50 & 7.18 & 9.36 \\
Log(bilateral GDP) & 7.46 & 7.41 & 3.08 & -2.15 & 18.11 \\
PTA & 0.22 & 0.00 & 0.41 & 0 & 1 \\
Log(distance) & 8.73 & 8.92 & 0.78 & 4.74 & 9.89 \\
Common border & 0.02 & 0.00 & 0.14 & 0 & 1 \\
Common language & 0.14 & 0.00 & 0.35 & 0 & 1 \\
Colony & 0.01 & 0.00 & 0.09 & 0 & 1 \\
MR PTA & 0.25 & -0.05 & 0.81 & -0.18 & 7.29 \\
MR Log(distance) & 10.66 & -3.39 & 46.88 & -7.59 & 481.69 \\
MR Common border & 0.00 & -0.05 & 0.15 & -0.05 & 1.56 \\
MR Common language & 0.20 & -0.07 & 1.32 & -0.10 & 13.54 \\
MR Colony & 0.04 & -0.01 & 0.22 & -0.01 & 2.51 \\
\hline \hline
\end{tabular}

Descriptive statistics computed from the sample of column (6) of Table 4 - except for Log(remoteness)

Descriptive statistics for $\log$ (remoteness) computed from the sample of column (6) of Table 5 


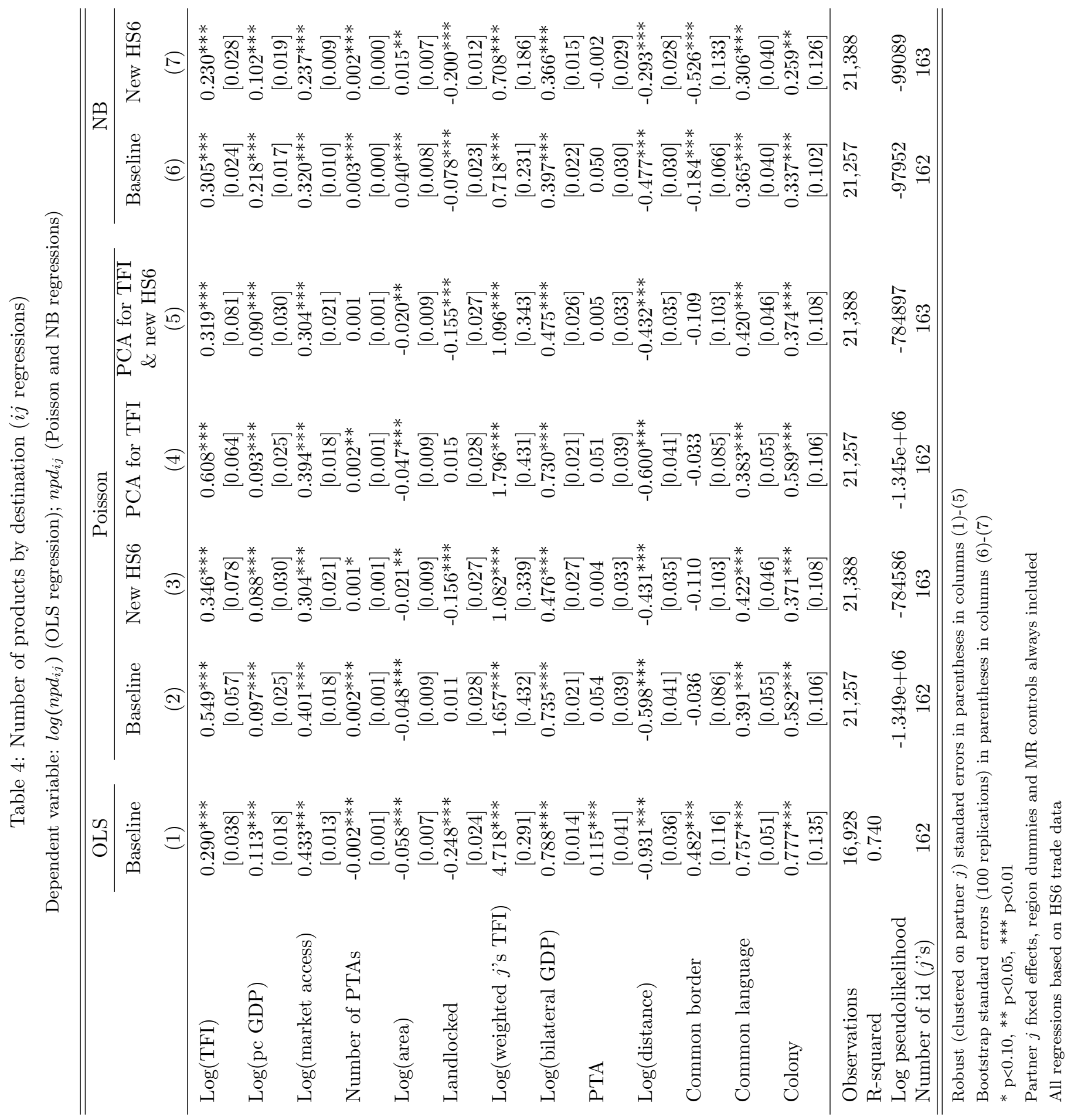




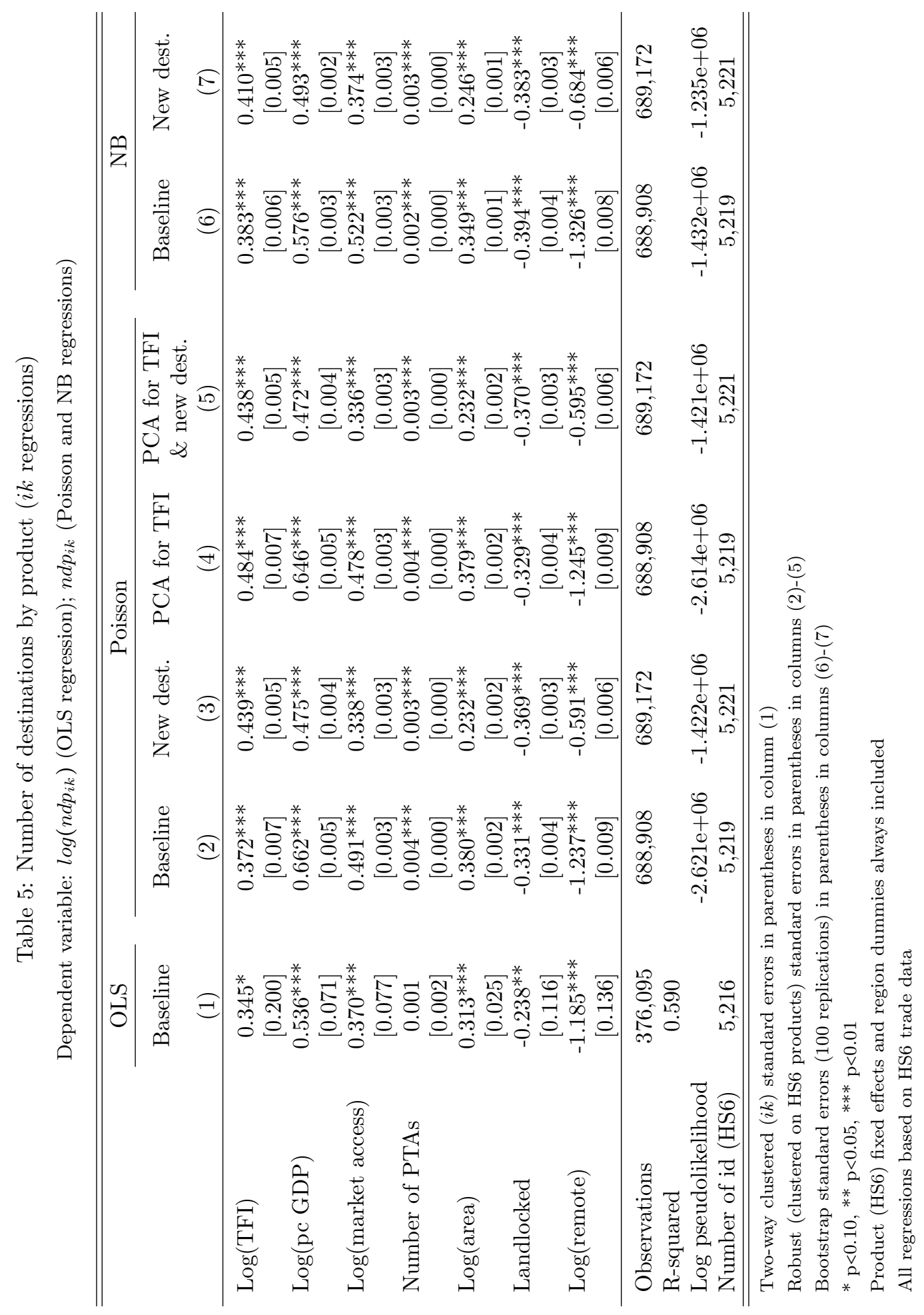




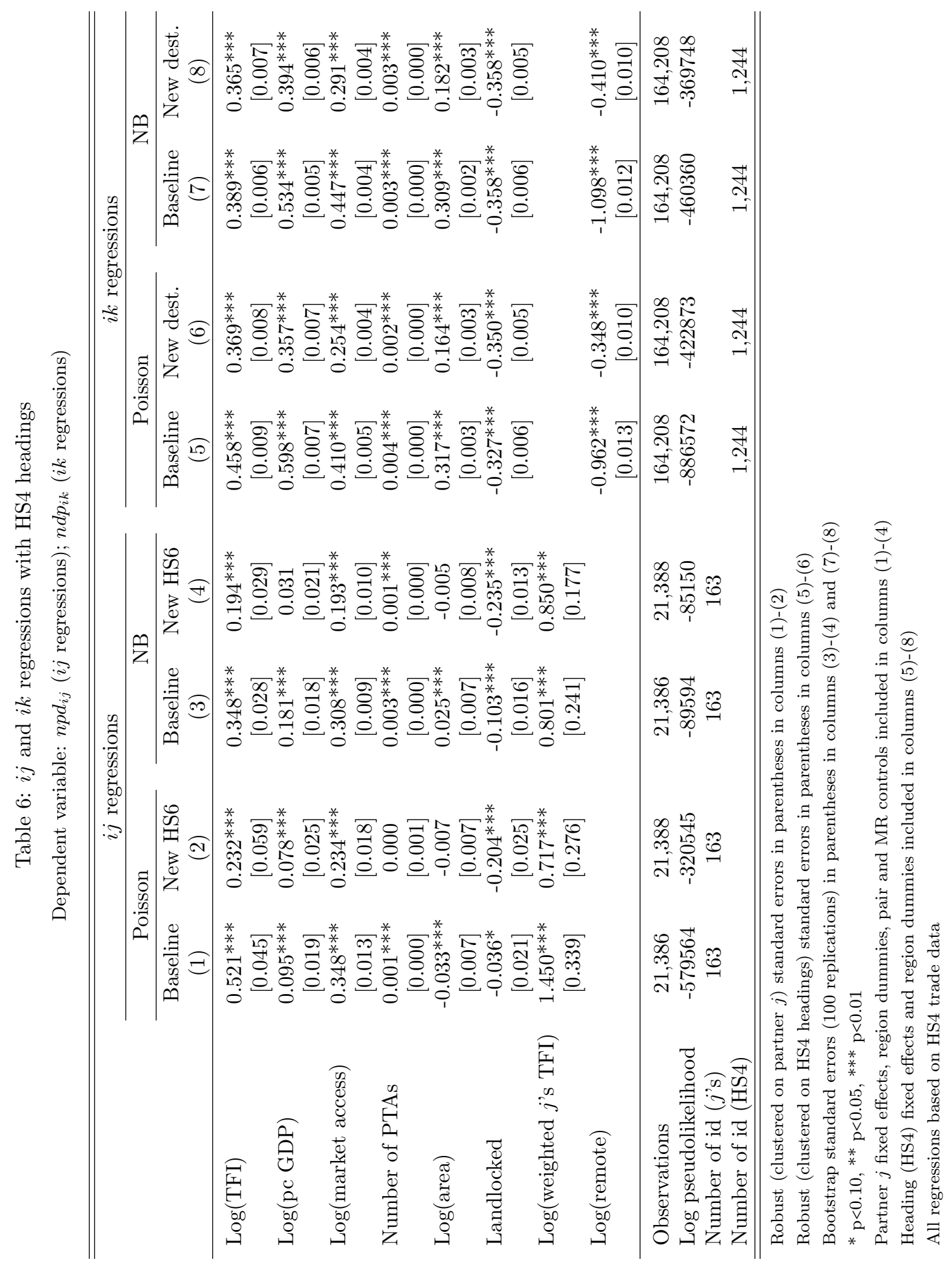


Table 7: Hummels-Klenow extensive margins Dependent variable: $e m_{i j}$ ( $i j$ regressions); $e m_{i k}$ ( $i k$ regressions)

\begin{tabular}{lccccc}
\hline \hline & \multicolumn{2}{c}{$i j$ regressions } & & \multicolumn{2}{c}{$i k$ regressions } \\
\cline { 2 - 3 } \cline { 5 - 6 } & Baseline & New HS6 & & Baseline & New dest. \\
& $(1)$ & $(2)$ & & $(3)$ & $(4)$ \\
\hline $\log (\mathrm{TFI})$ & $0.457^{* * *}$ & 0.118 & & $0.339^{* * *}$ & $-0.180^{* * *}$ \\
& {$[0.054]$} & {$[0.091]$} & & {$[0.015]$} & {$[0.017]$} \\
$\log ($ pc GDP $)$ & $0.249^{* * *}$ & $0.134^{* * *}$ & & $0.599^{* * *}$ & $0.586^{* * *}$ \\
$\log ($ market access $)$ & {$[0.023]$} & {$[0.041]$} & & {$[0.008]$} & {$[0.006]$} \\
& $0.285^{* * *}$ & $0.155^{* * *}$ & & $0.504^{* * *}$ & $0.387^{* * *}$ \\
Number of PTAs & {$[0.019]$} & {$[0.030]$} & & {$[0.006]$} & {$[0.006]$} \\
& $-0.001^{*}$ & -0.001 & & $0.004^{* * *}$ & $0.003^{* * *}$ \\
$\log ($ area $)$ & {$[0.000]$} & {$[0.001]$} & & {$[0.000]$} & {$[0.000]$} \\
& $-0.018^{* *}$ & -0.009 & & $0.428^{* * *}$ & $0.283^{* * *}$ \\
$\operatorname{Landlocked}$ & {$[0.008]$} & {$[0.012]$} & & {$[0.002]$} & {$[0.002]$} \\
& $-0.087^{* * *}$ & $-0.200^{* * *}$ & & $-0.172^{* * *}$ & $-0.202^{* * *}$ \\
$\log ($ weighted j's TFI) & {$[0.028]$} & {$[0.045]$} & & {$[0.008]$} & {$[0.008]$} \\
& 0.592 & 0.219 & & & \\
Log(remote) & {$[0.386]$} & {$[0.658]$} & & & \\
& & & & $-1.608^{* * *}$ & $-0.932^{* * *}$ \\
\hline Observations & 16,881 & 18,478 & & 370,035 & 407,097 \\
Log pseudolikelihood & -3994.8 & -2127.7 & & -118261.8 & -94469.8 \\
\hline \hline
\end{tabular}

Generalized Linear Model (GLM) regressions in all columns

Robust (clustered on partner $j$ ) standard errors in parentheses in columns (1)-(2)

Robust (clustered on HS6 products) standard errors in parentheses in columns (3)-(4)

* $\mathrm{p}<0.10,{ }^{* *} \mathrm{p}<0.05,{ }^{* * *} \mathrm{p}<0.01$

Partner $j$ dummies, region dummies, pair and MR controls included in columns (1)-(2)

Product (HS6) and region dummies included in columns (3)-(4)

All regressions based on HS6 trade data 
Table 8: Results with Doing Business variables

\begin{tabular}{|c|c|c|c|c|c|c|}
\hline \multicolumn{7}{|c|}{ ij regressions, dependent variable: $n_{p d} d_{i j}$} \\
\hline & \multicolumn{3}{|c|}{ NB baseline } & \multicolumn{3}{|c|}{ NB new HS6 } \\
\hline & (1) & $(2)$ & $(3)$ & (4) & $(5)$ & (6) \\
\hline $\log (\mathrm{DB}$ docs $)$ & $\begin{array}{c}0.183^{* * *} \\
{[0.015]}\end{array}$ & & & $\begin{array}{c}0.194^{* * *} \\
{[0.012]}\end{array}$ & & \\
\hline $\log (\mathrm{DB} \cos \mathrm{t})$ & & $\begin{array}{c}0.202^{* * *} \\
{[0.017]}\end{array}$ & & & $\begin{array}{c}0.210^{* * *} \\
{[0.009]}\end{array}$ & \\
\hline $\log (\mathrm{DB}$ time $)$ & & & $\begin{array}{c}0.214^{* * *} \\
{[0.014]}\end{array}$ & & & $\begin{array}{c}0.167^{* * *} \\
{[0.014]}\end{array}$ \\
\hline Observations & 20,613 & 20,613 & 20,613 & 20,740 & 20,740 & 20,740 \\
\hline Log pseudolikelihood & -95679 & -95585 & -95399 & -96559 & -96410 & -96376 \\
\hline Number of id (j's) & 162 & 162 & 162 & 163 & 163 & 163 \\
\hline
\end{tabular}

$i k$ regressions, dependent variable: $n d p_{i k}$

\begin{tabular}{|c|c|c|c|c|c|c|}
\hline & \multicolumn{3}{|c|}{ NB baseline } & \multicolumn{3}{|c|}{ NB new dest. } \\
\hline & $(1)$ & $(2)$ & $(3)$ & (4) & $(5)$ & $(6)$ \\
\hline $\log (\mathrm{DB}$ docs $)$ & $\begin{array}{c}0.078^{* * *} \\
{[0.003]}\end{array}$ & & & $\begin{array}{c}0.169^{* * *} \\
{[0.003]}\end{array}$ & & \\
\hline $\log (\mathrm{DB}$ cost $)$ & & $\begin{array}{c}0.330 * * * \\
{[0.003]}\end{array}$ & & & $\begin{array}{c}0.212^{* * *} \\
{[0.002]}\end{array}$ & \\
\hline $\log (\mathrm{DB}$ time $)$ & & & $\begin{array}{c}0.088^{* * *} \\
{[0.003]}\end{array}$ & & & $\begin{array}{c}0.213^{* * *} \\
{[0.002]}\end{array}$ \\
\hline Observations & 668,032 & 668,032 & 668,032 & 668,288 & 668,288 & 668,288 \\
\hline Log pseudolikelihood & $-1.410 \mathrm{e}+06$ & $-1.401 e+06$ & $-1.405 \mathrm{e}+06$ & $-1.210 \mathrm{e}+06$ & $-1.208 \mathrm{e}+06$ & $-1.205 \mathrm{e}+06$ \\
\hline Number of id (HS6) & 5,219 & 5,219 & 5,219 & 5,221 & 5,221 & 5,221 \\
\hline
\end{tabular}

Bootstrap standard errors (100 replications) in parentheses

${ }^{*} \mathrm{p}<0.10,{ }^{* *} \mathrm{p}<0.05,{ }^{* * *} \mathrm{p}<0.01$

Partner $j$ fixed effects, region dummies, exporter and MR controls always included in $i j$ regressions

Product (HS6) fixed effects and region dummies included in $i k$ regressions

All regressions based on HS6 trade data 
Table 9: ij regressions with income group sub-samples

Dependent variable: $n p d_{i j}$

\begin{tabular}{|c|c|c|c|c|}
\hline & $\begin{array}{c}\text { Poisson baseline } \\
\text { (1) }\end{array}$ & $\begin{array}{c}\text { Poisson new HS6 } \\
(2)\end{array}$ & $\begin{array}{c}\text { NB baseline } \\
(3)\end{array}$ & $\begin{array}{c}\text { NB new HS6 } \\
(4)\end{array}$ \\
\hline \multicolumn{5}{|c|}{ DD subsample: $i=$ developed, $j=$ developed } \\
\hline $\log (\mathrm{TFI})$ & $\begin{array}{c}0.529^{* * *} \\
{[0.051]}\end{array}$ & $\begin{array}{c}0.589^{* * *} \\
{[0.067]}\end{array}$ & $\begin{array}{c}0.414^{* * *} \\
{[0.035]}\end{array}$ & $\begin{array}{c}0.414^{* * *} \\
{[0.043]}\end{array}$ \\
\hline Observations & 5,359 & 5,425 & 5,359 & 5,425 \\
\hline Log pseudolikelihood & -408360 & -196406 & -30534 & -28399 \\
\hline Number of id ( $j$ 's) & 81 & 82 & 81 & 82 \\
\hline \multicolumn{5}{|c|}{ DG subsample: $i=$ developed, $j=$ developing } \\
\hline $\log (\mathrm{TFI})$ & $\begin{array}{c}0.514^{* * *} \\
{[0.192]}\end{array}$ & $\begin{array}{c}0.122 \\
{[0.253]}\end{array}$ & $\begin{array}{c}0.480 * * * \\
{[0.055]}\end{array}$ & $\begin{array}{c}0.299^{* * *} \\
{[0.047]}\end{array}$ \\
\hline Observations & 5,427 & 5,427 & 5,427 & 5,427 \\
\hline Log pseudolikelihood & -389952 & -240605 & -25463 & -25839 \\
\hline Number of id $(j$ 's $)$ & 81 & 81 & 81 & 81 \\
\hline \multicolumn{5}{|c|}{ GD subsample: $i=$ developing, $j=$ developed } \\
\hline $\log (\mathrm{TFI})$ & $\begin{array}{c}0.208^{* *} \\
{[0.096]}\end{array}$ & $\begin{array}{c}0.177^{* * *} \\
{[0.059]}\end{array}$ & $\begin{array}{c}0.363^{* * *} \\
{[0.054]}\end{array}$ & $\begin{array}{c}0.200^{* * *} \\
{[0.035]}\end{array}$ \\
\hline Observations & 5,265 & 5,330 & 5,265 & 5,330 \\
\hline Log pseudolikelihood & -141210 & -101560 & -22299 & -22466 \\
\hline Number of id (j's) & 81 & 82 & 81 & 82 \\
\hline \multicolumn{5}{|c|}{ GG subsample: $i=$ developing, $j=$ developing } \\
\hline $\log (\mathrm{TFI})$ & $\begin{array}{c}0.640^{* * *} \\
{[0.215]}\end{array}$ & $\begin{array}{l}0.279 * \\
{[0.144]}\end{array}$ & $\begin{array}{l}0.185^{*} \\
{[0.097]}\end{array}$ & $\begin{array}{c}0.057 \\
{[0.063]}\end{array}$ \\
\hline Observations & 5,206 & 5,206 & 5,206 & 5,206 \\
\hline Log pseudolikelihood & -130143 & -121028 & -16774 & -19255 \\
\hline Number of id (j's) & 81 & 81 & 81 & 81 \\
\hline
\end{tabular}

Robust (clustered on partner $j$ ) standard errors in parentheses in columns (1)-(2)

Bootstrap standard errors (100 replications) in parentheses in columns (3)-(4)

* $\mathrm{p}<0.10,{ }^{* *} \mathrm{p}<0.05,{ }^{* * *} \mathrm{p}<0.01$

Partner $j$ fixed effects, region dummies, exporter and MR controls always included

All regressions based on HS6 trade data 
Table 10: Simulation results based on NB $i j$ regressions

Panel (a): Simulations based on $n p d_{i j}$ computed from HS6 trade data

\begin{tabular}{|c|c|c|c|c|}
\hline & \multicolumn{2}{|c|}{ Regional median } & \multicolumn{2}{|c|}{ Global median } \\
\hline & $\begin{array}{c}\text { Baseline } \\
\text { (1) }\end{array}$ & $\begin{array}{c}\text { New HS6 } \\
(2)\end{array}$ & $\begin{array}{c}\text { Baseline } \\
(3)\end{array}$ & $\begin{array}{c}\text { New HS6 } \\
(4)\end{array}$ \\
\hline Sub-Saharan Africa & $15.5 \%$ & $12.6 \%$ & $20.8 \%$ & $15.7 \%$ \\
\hline East Asia and Pacific & $6.9 \%$ & $5.6 \%$ & $7.3 \%$ & $5.5 \%$ \\
\hline Europe and Central Asia & $7.5 \%$ & $6.1 \%$ & $6.7 \%$ & $5.1 \%$ \\
\hline Latin America and the Caribbean & $14.2 \%$ & $11.6 \%$ & $16.2 \%$ & $12.2 \%$ \\
\hline Middle East and North Africa & $5.6 \%$ & $4.5 \%$ & $8.7 \%$ & $6.6 \%$ \\
\hline South Asia & $5.5 \%$ & $4.5 \%$ & $6.4 \%$ & $4.8 \%$ \\
\hline
\end{tabular}

Columns (1) and (3) based on column (6) of Table 4

Columns (2) and (4) based on column (7) of Table 4

Panel (b): Simulations based on $n p d_{i j}$ computed from HS4 trade data

\begin{tabular}{|c|c|c|c|c|}
\hline & \multicolumn{2}{|c|}{ Regional median } & \multicolumn{2}{|c|}{ Global median } \\
\hline & $\begin{array}{c}\text { Baseline } \\
(1)\end{array}$ & $\begin{array}{c}\text { New HS4 } \\
(2)\end{array}$ & $\begin{array}{c}\text { Baseline } \\
(3)\end{array}$ & $\begin{array}{c}\text { New HS4 } \\
(4)\end{array}$ \\
\hline Sub-Saharan Africa & $17.2 \%$ & $11.6 \%$ & $23.7 \%$ & $13.2 \%$ \\
\hline East Asia and Pacific & $7.6 \%$ & $5.2 \%$ & $8.3 \%$ & $4.6 \%$ \\
\hline Europe and Central Asia & $8.3 \%$ & $5.6 \%$ & $7.7 \%$ & $4.3 \%$ \\
\hline Latin America and the Caribbean & $15.7 \%$ & $10.6 \%$ & $18.5 \%$ & $10.3 \%$ \\
\hline Middle East and North Africa & $6.2 \%$ & $4.2 \%$ & $9.9 \%$ & $5.5 \%$ \\
\hline South Asia & $6.1 \%$ & $4.1 \%$ & $7.3 \%$ & $4.1 \%$ \\
\hline
\end{tabular}

Columns (1) and (3) based on column (1) of Table 6

Columns (2) and (4) based on column (2) of Table 6 
Table 11: Simulation results based on NB $i k$ regressions

Panel (a): Simulations based on $n d p_{i k}$ computed from HS6 trade data

\begin{tabular}{|c|c|c|c|c|}
\hline & \multicolumn{2}{|c|}{ Regional median } & \multicolumn{2}{|c|}{ Global median } \\
\hline & $\begin{array}{c}\text { Baseline } \\
(1)\end{array}$ & $\begin{array}{c}\text { New dest. } \\
(2)\end{array}$ & $\begin{array}{c}\text { Baseline } \\
(3)\end{array}$ & $\begin{array}{c}\text { New dest. } \\
(4)\end{array}$ \\
\hline Sub-Saharan Africa & $20.7 \%$ & $22.1 \%$ & $26.1 \%$ & $27.9 \%$ \\
\hline East Asia and Pacific & $9.5 \%$ & $10.1 \%$ & $9.1 \%$ & $9.8 \%$ \\
\hline Europe and Central Asia & $10.3 \%$ & $11.0 \%$ & $8.4 \%$ & $9.0 \%$ \\
\hline Latin America and the Caribbean & $19.5 \%$ & $20.9 \%$ & $20.3 \%$ & $21.7 \%$ \\
\hline Middle East and North Africa & $7.7 \%$ & $8.2 \%$ & $10.9 \%$ & $11.7 \%$ \\
\hline South Asia & $7.6 \%$ & $8.1 \%$ & $8.1 \%$ & $8.6 \%$ \\
\hline
\end{tabular}

Columns (1) and (3) based on column (6) of Table 5

Columns (2) and (4) based on column (7) of Table 5

Panel (b): Simulations based on $n d p_{i k}$ computed from HS4 trade data

\begin{tabular}{|c|c|c|c|c|}
\hline & \multicolumn{2}{|c|}{ Regional median } & \multicolumn{2}{|c|}{ Global median } \\
\hline & $\begin{array}{c}\text { Baseline } \\
(1)\end{array}$ & $\begin{array}{c}\text { New dest. } \\
(2)\end{array}$ & $\begin{array}{c}\text { Baseline } \\
(3)\end{array}$ & $\begin{array}{c}\text { New dest. } \\
(4)\end{array}$ \\
\hline Sub-Saharan Africa & $21.0 \%$ & $19.7 \%$ & $26.5 \%$ & $24.9 \%$ \\
\hline East Asia and Pacific & $9.6 \%$ & $9.0 \%$ & $9.3 \%$ & $8.7 \%$ \\
\hline Europe and Central Asia & $10.4 \%$ & $9.8 \%$ & $8.6 \%$ & $8.0 \%$ \\
\hline Latin America and the Caribbean & $19.8 \%$ & $18.6 \%$ & $20.6 \%$ & $19.4 \%$ \\
\hline Middle East and North Africa & $7.8 \%$ & $7.3 \%$ & $11.1 \%$ & $10.4 \%$ \\
\hline South Asia & $7.7 \%$ & $7.2 \%$ & $8.2 \%$ & $7.7 \%$ \\
\hline
\end{tabular}

Columns (1) and (3) based on column (3) of Table 6

Columns (2) and (4) based on column (4) of Table 6 


\section{Appendix tables}

Table A-1: Mapping of OECD TFIs into DCNT and TFA provisions

\begin{tabular}{llcc}
\hline \hline & \multicolumn{1}{c}{ Indicator } & DCNT Rev. 18 & TFA \\
\hline A. & Information availability & Articles 1 and 2 & Articles 1 and 2 \\
B. & Involvement of the trade community & Article 2 & Article 2 \\
C. & Advance Rulings & Article 3 & Article 3 \\
D. & Appeal Procedures & Article 4 & Article 4 \\
E. & Fees and charges & Article 6.1 and 6.2 & Article 6.1 and 6.2 \\
F. & Formalities - Documents & Articles 7 and 10 & Articles 7 and 10 \\
G. & Formalities - Automation & Articles 7 and 10 & Articles 7 and 10 \\
H. & Formalities - Procedures & Articles 5,7 and 10 & Articles 5,7 and 10 \\
I. & Cooperation - Internal & Articles 9.1 and 12 & Articles 8.1 and 12 \\
J. & Cooperation - External & Articles 9.2 and 12 & Articles 8.2 and 12 \\
K. & Consularization & Article 8 & - \\
L. & Governance and Impartiality & - & - \\
M. & Transit fees and charges & Article 11 & Article 11 \\
N. & Transit formalities & Article 11 & Article 11 \\
O. & Transit guarantees & Article 11 & Article 11 \\
P. & Transit agreements and cooperation & Article 11 & Article 11 \\
\hline \hline
\end{tabular}

TFI's stand for "Trade Facilitation Indicators"

DCNT stands for (WTO's) "Draft Consolidated Negotiating Text"

TFA stands for (WTO's) "Trade Facilitation Agreement"

Source: Moïsé et al. (2011) 
Table A-2: List of countries with OECD TFI data, by World Bank region

\begin{tabular}{|c|c|c|c|}
\hline \multicolumn{4}{|l|}{ Sub-Saharan Africa } \\
\hline Angola (1994) & Benin (1963) & Botswana (1987) & Burkina Faso (1963) \\
\hline Burundi (1965) & Cameroon (1963) & Congo (1963) & Côte d'Ivoire (1963) \\
\hline Ethiopia* & Gabon (1963) & Gambia (1965) & Ghana (1957) \\
\hline Kenya (1964) & Lesotho (1988) & Liberia* & Madagascar (1963) \\
\hline Malawi (1964) & Mali (1993) & Mauritius (1970) & Mozambique (1992) \\
\hline Namibia (1992) & Nigeria $(1960)$ & Rwanda (1966) & Senegal (1963) \\
\hline Sierra Leone (1961) & South Africa (1948) & Swaziland (1993) & Tanzania (1961) \\
\hline Togo (1964) & Uganda (1962) & Zambia (1982) & Zimbabwe (1948) \\
\hline \multicolumn{4}{|l|}{ East Asia and Pacific } \\
\hline Brunei Dar. (1993) & Cambodia (2004) & China (2001) & Chinese Taipei (2002) \\
\hline Fiji (1993) & Hong Kong, China (1986) & Indonesia (1950) & Korea, Rep. (1967) \\
\hline Malaysia (1957) & Mongolia (1997) & Papua N. G. (1994) & Philippines (1979) \\
\hline Singapore (1973) & Thailand (1982) & Viet Nam (2007) & \\
\hline \multicolumn{4}{|l|}{ Europe and Central Asia } \\
\hline Albania $(2000)$ & Armenia (2003) & Azerbaijan* & Belarus* \\
\hline Bosnia and Herzegovina* & Bulgaria (1996) & Croatia $(2000)$ & Czech Rep. (1993) \\
\hline Georgia (2000) & Hungary (1973) & Kazakhstan* & Kyrgyz Rep. (1998) \\
\hline Latvia (1999) & Lithuania (2001) & Moldova (2001) & Montenegro (2012) \\
\hline Poland (1967) & Romania (1971) & Russian Fed. (2012) & Serbia* \\
\hline Slovak Republic (1993) & The FYROM (2003) & Turkey (1951) & Ukraine (2008) \\
\hline \multicolumn{4}{|c|}{ Latin America and the Caribbean } \\
\hline Antigua and Barb. (1987) & Argentina (1967) & Barbados (1967) & Belize (1983) \\
\hline Bolivia (1990) & Brazil (1948) & Colombia (1981) & Costa Rica (1990) \\
\hline Cuba (1948) & Dominican Rep. (1950) & Ecuador (1996) & El Salvador (1991) \\
\hline Guatemala (1991) & Honduras (1994) & Jamaica (1963) & Mexico (1986) \\
\hline Nicaragua (1950) & Panama (1997) & Paraguay (1994) & Peru (1951) \\
\hline Suriname (1978) & Trinidad and Tob. (1962) & Uruguay (1953) & Venezuela (1990) \\
\hline \multicolumn{4}{|c|}{ Middle East and North Africa } \\
\hline Algeria* & Bahrain (1993) & Jordan (2000) & Kuwait (1963) \\
\hline Lebanon* & Morocco (1987) & Oman $(2000)$ & Qatar (1994) \\
\hline Saudi Arabia (2005) & Tunisia (1990) & UAE (1994) & \\
\hline \multicolumn{4}{|l|}{ South Asia } \\
\hline Bangladesh (1972) & Bhutan* & India (1948) & Nepal (2004) \\
\hline Pakistan (1948) & Sri Lanka (1948) & & \\
\hline \multicolumn{4}{|l|}{ Offshore } \\
\hline \multicolumn{4}{|l|}{ Bahamas* } \\
\hline \multicolumn{4}{|l|}{ Industrial } \\
\hline Australia (1948) & Belgium (1948) & Canada (1948) & Cyprus (1963) \\
\hline Denmark (1950) & France (1948) & Germany (1951) & Greece (1950) \\
\hline Italy (1950) & Japan (1955) & Malta (1964) & Netherlands (1948) \\
\hline New Zealand (1948) & Norway (1948) & Portugal (1962) & Spain (1963) \\
\hline Sweden (1950) & Switzerland (1966) & United Kingdom (1948) & United States (1948) \\
\hline
\end{tabular}




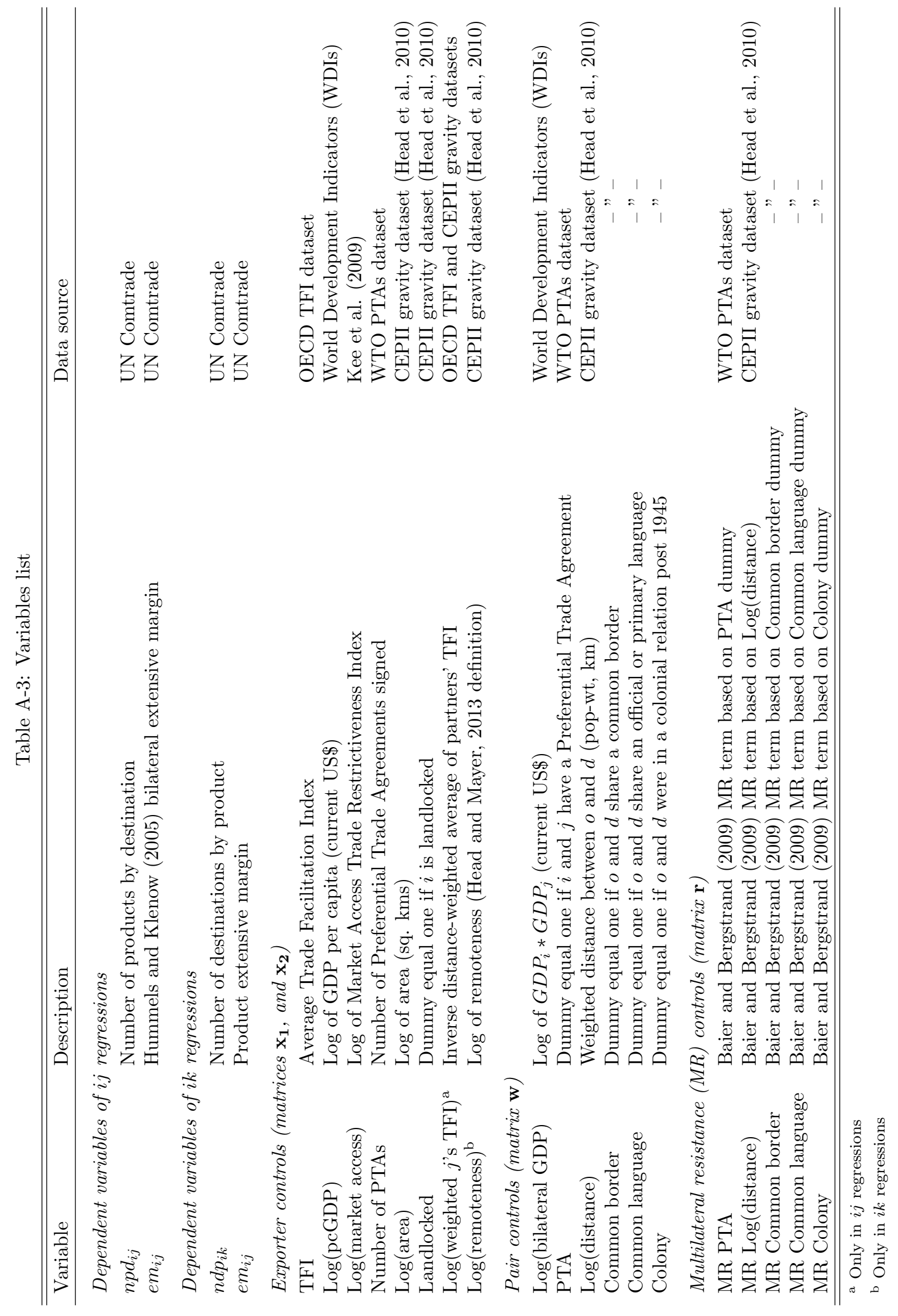




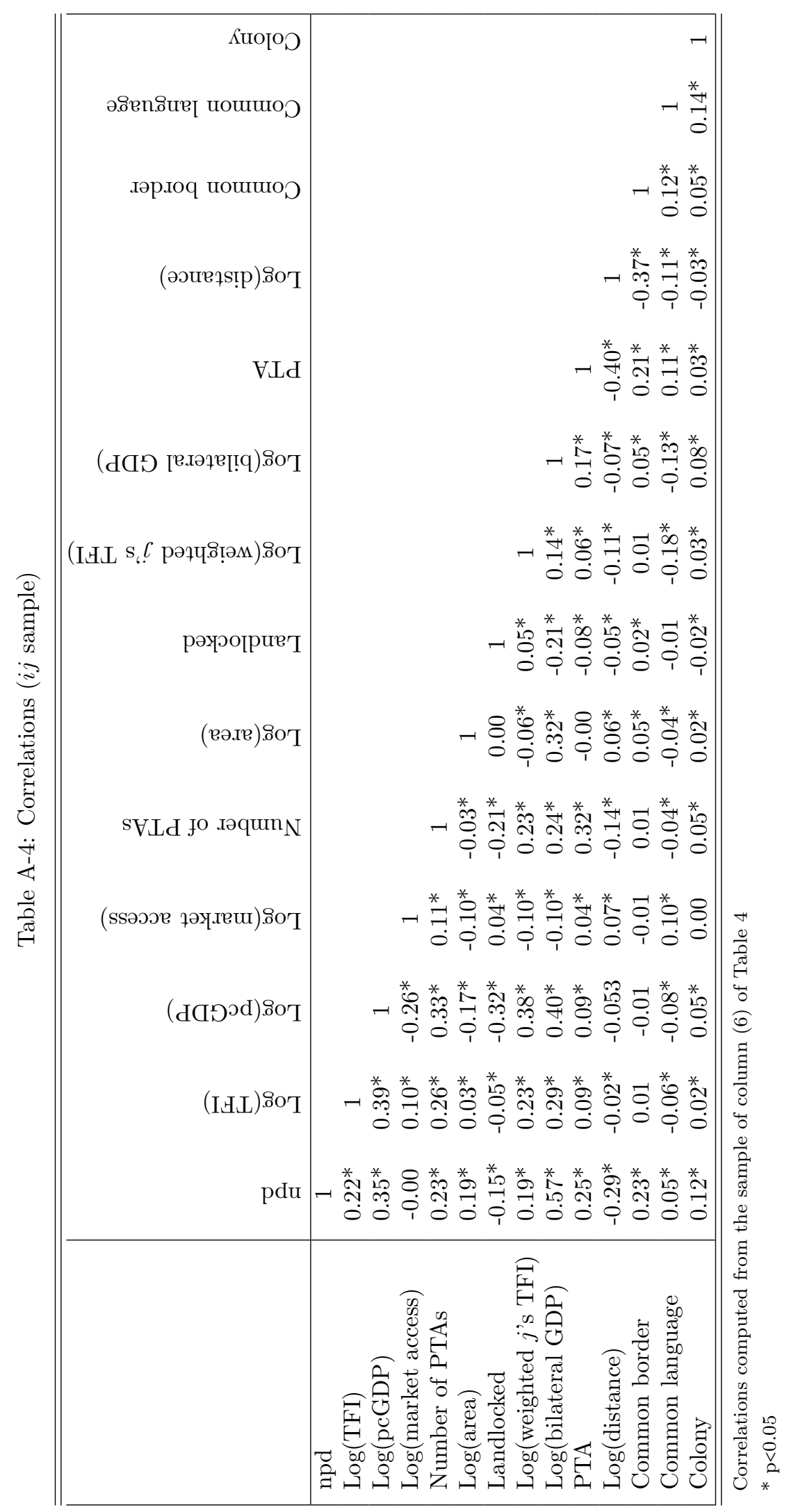


Table A-5: Correlations (ik sample)

\begin{tabular}{|c|c|c|c|c|c|c|c|c|}
\hline & : & 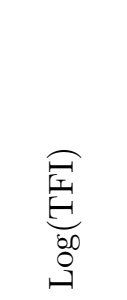 & 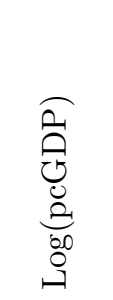 & 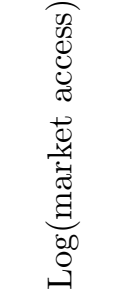 & 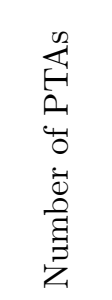 & 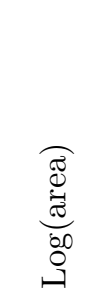 & 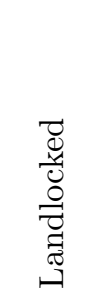 & 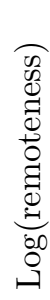 \\
\hline npd & 1 & & & & & & & \\
\hline $\log (\mathrm{TFI})$ & $0.22 *$ & 1 & & & & & & \\
\hline $\log (p c G D P)$ & $0.35^{*}$ & $0.38^{*}$ & 1 & & & & & \\
\hline Log(market access) & 0.00 & $0.10^{*}$ & $-0.26^{*}$ & 1 & & & & \\
\hline Number of PTAs & $0.22^{*}$ & $0.26^{*}$ & $0.33^{*}$ & $0.11^{*}$ & 1 & & & \\
\hline Log(area) & $0.19^{*}$ & $0.03^{*}$ & $-0.17^{*}$ & $-0.10^{*}$ & $-0.03^{*}$ & 1 & & \\
\hline Landlocked & $-0.15^{*}$ & $-0.05^{*}$ & $-0.32 *$ & $0.04^{*}$ & $-0.21^{*}$ & 0.00 & 1 & \\
\hline Log(remoteness) & $-0.35^{*}$ & $-0.34^{*}$ & $-0.60^{*}$ & $0.16^{*}$ & $-0.47^{*}$ & $0.22 *$ & $0.08^{*}$ & 1 \\
\hline
\end{tabular}

Correlations computed from the sample of column (6) of Table 5

$* \mathrm{p}<0.05$

Table A-6: Summary statistics, Hummels-Klenow extensive margins

\begin{tabular}{lcccccccc}
\hline \hline & \multicolumn{3}{c}{$e m_{i j}$} & & \multicolumn{3}{c}{$e m_{i k}$} \\
\cline { 2 - 3 } \cline { 9 - 10 } World Bank region & mean & $\mathrm{sd}$ & $\mathrm{N}$ & & mean & $\mathrm{sd}$ & $\mathrm{N}$ \\
\hline Sub-Saharan Africa & 0.06 & 0.12 & 3509 & & 0.07 & 0.15 & 50954 \\
East Asia and Pacific & 0.27 & 0.26 & 1867 & & 0.37 & 0.33 & 46099 \\
Europe and Central Asia & 0.16 & 0.21 & 2985 & & 0.19 & 0.24 & 75335 \\
Latin America and Caribbean & 0.10 & 0.17 & 2991 & & 0.13 & 0.20 & 62038 \\
Middle East and North Africa & 0.12 & 0.16 & 1471 & & 0.12 & 0.18 & 28156 \\
South Asia & 0.15 & 0.21 & 805 & & 0.28 & 0.32 & 15147 \\
Offshore & 0.04 & 0.07 & 106 & & 0.05 & 0.09 & 1242 \\
Industrial & 0.40 & 0.29 & 3147 & & 0.47 & 0.33 & 91064 \\
Whole sample & 0.18 & 0.24 & 16881 & & 0.25 & 0.30 & 370035 \\
\hline \hline
\end{tabular}

Descriptive statistics for $e m_{i j}$ computed from the sample of column (1) of Table 7

Descriptive statistics for $e m_{i k}$ computed from the sample of column (3) of Table 7

All descriptive statistics based on HS6 trade data

Table A-7: Correlation between TFI and Doing business variables

\begin{tabular}{|l|cccc|}
\hline \hline & TFI & DB docs & DB cost & DB time \\
\hline TFI & 1 & & & \\
DB docs & $0.44^{*}$ & 1 & & \\
DB cost & $0.30^{*}$ & $0.37^{*}$ & 1 & \\
DB time & $0.51^{*}$ & $0.66^{*}$ & $0.45^{*}$ & 1 \\
\hline \hline
\end{tabular}

Correlations computed from the sample of column (1) of Table 8

* $\mathrm{p}<0.05$ 